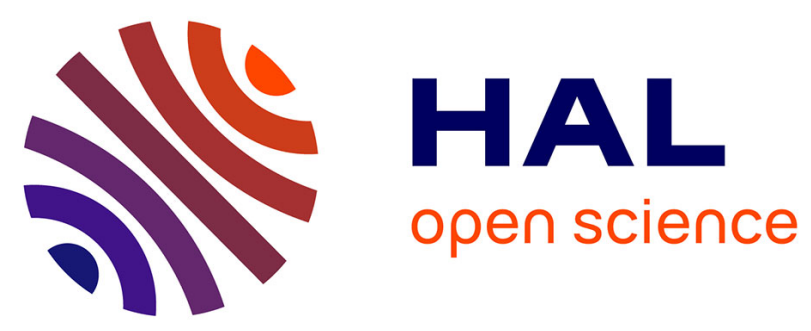

\title{
Influence of a static torque on plasticity and asperity-induced closure effects during fatigue crack growth in bainitic steel cylinders loaded in push-pull
}

\author{
Louis Petureau, Véronique Doquet, Benjamin Dieu
}

\section{To cite this version:}

Louis Petureau, Véronique Doquet, Benjamin Dieu. Influence of a static torque on plasticity and asperity-induced closure effects during fatigue crack growth in bainitic steel cylinders loaded in pushpull. International Journal of Fatigue, 2022, 155, pp.106628. 10.1016/j.ijfatigue.2021.106628 . hal03409904

\author{
HAL Id: hal-03409904 \\ https://hal.science/hal-03409904
}

Submitted on 30 Oct 2021

HAL is a multi-disciplinary open access archive for the deposit and dissemination of scientific research documents, whether they are published or not. The documents may come from teaching and research institutions in France or abroad, or from public or private research centers.
L'archive ouverte pluridisciplinaire $\mathbf{H A L}$, est destinée au dépôt et à la diffusion de documents scientifiques de niveau recherche, publiés ou non, émanant des établissements d'enseignement et de recherche français ou étrangers, des laboratoires publics ou privés. 


\title{
Influence of a static torque on plasticity and asperity-induced closure effects
}

\author{
during fatigue crack growth in bainitic steel cylinders loaded in push-pull. \\ Louis Petureau ${ }^{1}$, Véronique Doquet ${ }^{1 *}$, Benjamin Dieu ${ }^{1,2,3}$ \\ ${ }^{1}$ Laboratoire de Mécanique des Solides, CNRS UMR 7649, Ecole Polytechnique, Institut \\ Polytechnique de Paris, route de Saclay, 91128 Palaiseau cedex, France \\ ${ }^{2}$ Laboratoire de Tribologie et Dynamique des Systèmes, CNRS UMR 5513, Ecole Centrale de \\ Lyon, 36 avenue Guy de Collongue 69134 Ecully, France \\ ${ }^{3}$ Naval Group, site de Nantes-Indret, Rue d'Indret, 44620 La Montagne, France
}

*Corresponding author: veronique.doquet@polytechnique.edu

\begin{abstract}
Mode I fatigue crack growth with a superimposed static torque was investigated in bainitic steel. The torque had little effect on crack growth kinetics and path. However, the nonsingular stress parallel to the crack front, and bending stresses due to eccentric crack growth triggered crack twisting, even in mode I. A progressive increase in crack sliding displacement was due to a rise in elastic torsional compliance, but also to plastic ratchetting at the crack tip, and to a progressive shearing of crack face asperities, which reduced the enhancement of roughness-induced closure by the torque, however shown to enhance plasticity-induced closure.
\end{abstract}

Keyword fatigue crack; mixed-mode I + III; closure effects; $\mathrm{T}$ stress; finite element simulations

\section{Introduction.}

Rotating shafts submitted to bending under self-weight, and a steady superimposed torque are quite common in industrial devices, like power generators, wind turbines, boat propulsion systems, pumps, and many others. They have to be designed against fatigue failure due to the inwards growth of one or several cracks initiated from geometrically-induced or frettinginduced surface stress concentrations. Many papers report case studies on such fractures [1-12]. Surface cracks in shafts submitted to a static torque undergo both static mode II and mode III in various proportions, depending on the position along their curved fronts. The effects of both static shear mode loadings on mode I fatigue crack growth are thus relevant for the durability of such structures. This engineering problem thus triggered basic research on the influence of a 
steady mode III [13-17], steady mode II [18-21] or a combination of both [22-26], on mode I fatigue crack growth.

It has been shown that a static mode III loading slows down mode I fatigue crack growth (by a factor as high as 10 in fine grained steels and up to 50 in coarse grained Ti alloys [13-15]), and raises the threshold $\Delta \mathrm{K}_{\mathrm{I}}$, especially for low or negative $\mathrm{R}$ ratios (by a factor of 1.6 to 2 at high $\mathrm{K}_{\text {III, }}$ in chromium steel, depending on $\mathrm{R}$ [16]). This was attributed mostly to enhanced roughness-induced crack closure (RICC) [13-15], as a consequence of microscale crack twisting towards planes on which the torque induces an opening stress. However, in their comparative study of mode III-induced deceleration in steels, titanium and aluminum alloys, Hourlier \& Pineau [14] measured twist angles substantially smaller than predicted by the maximum tangential stress criterion (MTS):

$$
\tan (2 \phi)=\frac{2 K_{I I I}}{K_{I}(1-2 v)}
$$

, or even equal to zero in one of the investigated steels. They explained the different twist angles measured in different materials for the same mode mixity ratio using the maximum growth rate criterion (MGR) : crack twisting raises $\mathrm{K}_{\mathrm{Imax}}$, and the $\mathrm{R}$ ratio, but reduces $\Delta \mathrm{K}_{\mathrm{I}}$, and for materials in which the mode I kinetics is very sensitive to $\mathrm{K}_{\operatorname{Imax}}$ or $\mathrm{R}$, the growth rate on a twisted facet can become higher than on the original crack plane, this triggering crack twisting, while for materials in which the mode I kinetics is mainly controlled by $\Delta \mathrm{K}_{\mathrm{I}}$, no twisting should occur.

Note that in the steel which did not exhibit any crack twisting, a steady torque however reduced the mode I crack growth rate by approximately the same factor as in the other materials. This suggests that RICC might not be the only reason for the observed deceleration.

Some effects of the static mode III on crack tip plasticity (increase in plastic zone size, enhanced strain hardening) have been evoked by Tschegg et al, [16] and Da Fonte et al. [24], but only qualitatively, while those on plasticity-induced crack closure (PICC) have not been investigated so far.

A static mode II superimposed on cyclic mode I has been reported by Stanzl et al. [20] to reduce the growth rate of long cracks, for zero or negative $\mathrm{R}$ ratios, in a chromium steel, but to increase it for short cracks. This was rationalized by Doquet et al. [21] who showed that a static mode II has opposite effects on RICC (which it increases, due to a permanent shift of crack faces asperities) and on PICC (which it reduces, especially for zero or negative R ratios).

While the effect of a static mode III on RICC is expected to be relatively similar to that of a static mode II, since it permanently shifts crack faces asperities as well, the effects of a static mode III on crack tip plasticity and plasticity-induced closure deserve more attention than it has received until now. The present work investigates this question, through elastic-plastic finite element (FE) simulations.

On the other hand, Lu et al. [17], recently reported that in two steels, the reduction of the mode I crack growth rate by a superimposed static mode III did not increase indefinitely with $\mathrm{K}_{\text {III }}$, but saturated, above a material-dependent $\mathrm{K}_{\mathrm{III}}$. They suggested that this might be due to a wear-induced reduction of RICC at high $\mathrm{K}_{\mathrm{III}}$. The present work, which combines mode I crack growth test with a superimposed torque on circumferentially notched bainitic steel cylinders, and numerical simulations will also bring elements explaining why the beneficial effect of a steady torque does not increase indefinitely with the torque. 
The paper first introduces the experimental procedures, and the numerical tools that had to be developed to analyze properly the test results, in spite of an eccentric and non-circular crack growth. Then, the crack paths are described both at macroscale (crack front shape evolution) and microscale (crack face roughness, local crack twisting angles), and analyzed with respect to the stress intensity factors along the front. Then, the measured crack closure effects, and the observed ratchetting increase of the mean crack sliding displacement are described and analyzed, considering crack tip plasticity and plasticity-induced closure effects. 3D step by step simulations of crack growth, based on the mode I kinetics are shown to capture reasonably well the experimental data, but to be improved if the effect of a static mode III on crack closure is introduced. Finally, local crack twisting is shown to be triggered mostly by the rising, nonsingular tensile stress parallel to the crack front, rather than by the mode III component.

\section{Experimental procedures}

\section{II.1. Material and specimens}

A low alloy steel, with the composition indicated in Table 1 was used for this study.

\begin{tabular}{|c|c|c|c|c|c|c|c|c|c|}
\hline & $\mathrm{C}$ & $\mathrm{Mn}$ & $\mathrm{Si}$ & $\mathrm{Cr}$ & $\mathrm{P}$ & $\mathrm{S}$ & $\mathrm{Ni}$ & $\mathrm{Mo}$ & $\mathrm{Fe}$ \\
\hline Weight $\%$ & 0,19 & 1,29 & 0,18 & 0,14 & 0,008 & 0,004 & 0,70 & 0,47 & balance \\
\hline
\end{tabular}

Table 1. Chemical composition of the steel

The $0.2 \%$ yield stress of the steel is $520 \mathrm{MPa}$, its ultimate tensile strength $640 \mathrm{MPa}$, and its elongation at fracture $60 \%$. Figure 1 shows the bainitic microstructure of the material, with about $35 \mu \mathrm{m}$-large former austenite grains, in average, and nearly no texture, as shown by the pole figures derived from EBSD mappings.

a)
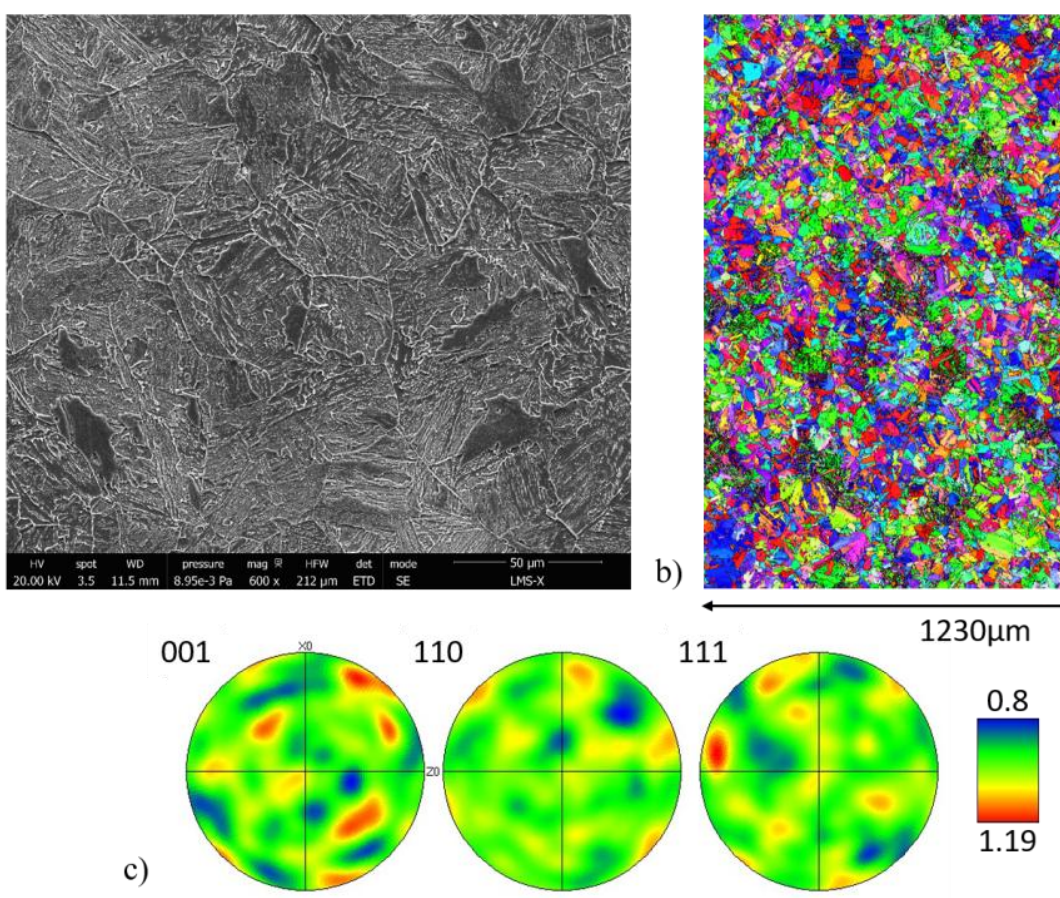

c)

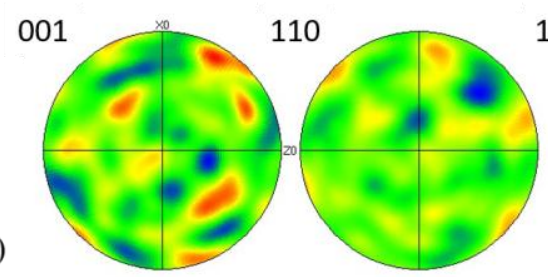

$1330 \mu \mathrm{m}$

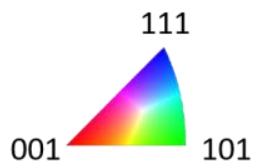

Figure 1: Microstructure of the steel.a) SEM observation b) EBSD mapping of crystal orientations (the color code refers to the Euler angles) and c) Pole figures derived from the EBSD mapping 
Circumferentially notched cylindrical specimens, with an outer diameter of $30 \mathrm{~mm}$ and a 2.4 $\mathrm{mm}$ deep notch were machined, according to the dimensions indicated on Figure 2.

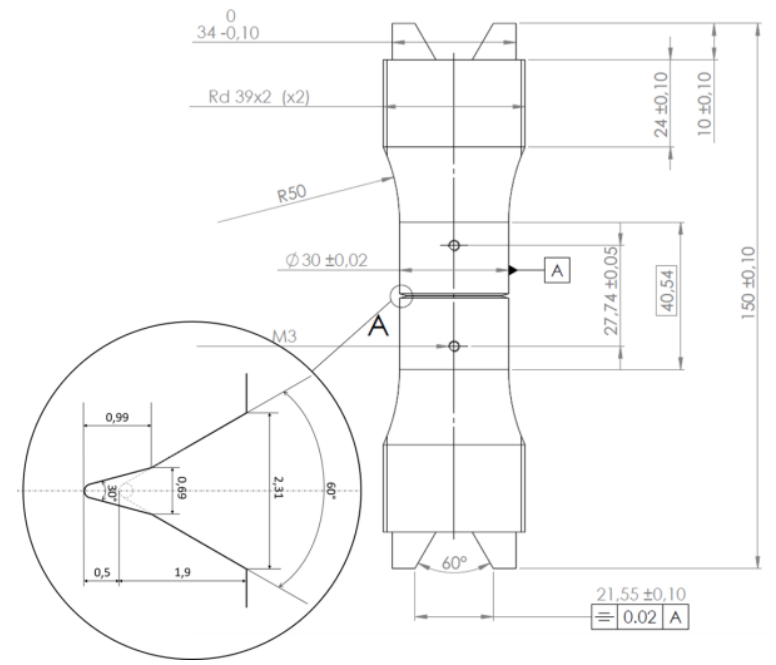

Figure 2: Geometry of the circumferentially notched specimens

\section{II.2. Testing procedures}

Before the mixed-mode fatigue crack growth tests, the specimens were precracked by the repeated compression technique [27], that Popovitch et al. [28] have shown to be efficient in obtaining a circular precrack front in cylindrical specimens. The technique relies on an initial compressive plastic flow of the material ahead of the notch root, which generates tensile residual stresses upon unloading. These tensile stresses allow crack initiation and a short propagation until the crack is stopped by the far-field cyclic compression. This technique is selfregulating, since the depth at which the crack stops growing is the same all around the circumference, even if crack initiation is not simultaneous. After 140000 compression cycles between -5 and $-150 \mathrm{kN}$, a reasonably circular precrack, $160 \pm 15 \mu \mathrm{m}$ deep, was obtained, in a reproducible way from one specimen to the other.

The crack growth tests were performed on a testing machine which allows combined tension/compression $( \pm 100 \mathrm{kN})$ and torsion $( \pm 600 \mathrm{Nm})$, loadings. A special attention was paid to the specimen alignment when mounting it on the testing machine. Different methods were used to monitor crack propagation during the tests (Figure 3). One or two pairs of black paint markers were drawn on a background of sprayed white paint (to enhance the contrast and facilitate the optical tracking of the markers) approximately $1 \mathrm{~mm}$ above and below the notch, and in the latter case, these markers were placed along two diametrically opposed generators. One or two 5.1 Mega pixels cameras fitted with telecentric lenses recorded 400 images of each marker pair per cycle, with a resolution around $3.5 \mu \mathrm{m} /$ pixel and a sub-pixel image correlation algorithm determined their relative vertical and horizontal displacements that is, the local crack opening (COD) and sliding (CSD) displacements respectively, with an accuracy of approximately 0.1 pixel, that is: $350 \mathrm{~nm}$. A mechanical extensometer with a gage length of $12 \mathrm{~mm}$, was placed mid-way of the angular positions of the two cameras, and recorded the opening displacement of the crack there. At last, the DC potential drop method was used. An electrical current circulated between the upper and lower ends of the specimen and two electric probes welded approximately $1 \mathrm{~mm}$ above and below the notch in an angular position diametrically opposed to that of the mechanical extensometer measured the potential drop there during crack propagation. Even though a permanent torque favors electrical contacts between crack face asperities, most of these contacts disappear with crack opening, at peak tensile load, when the DC potential drop signal is recorded, and this technique has been used successfully in several studies to monitor circumferential fatigue crack growth in mode I with a static mode III [13-15, 29]. That way, data on crack growth were collected at three (tests \#13 and \#14) or four (the other five tests) angular positions. 


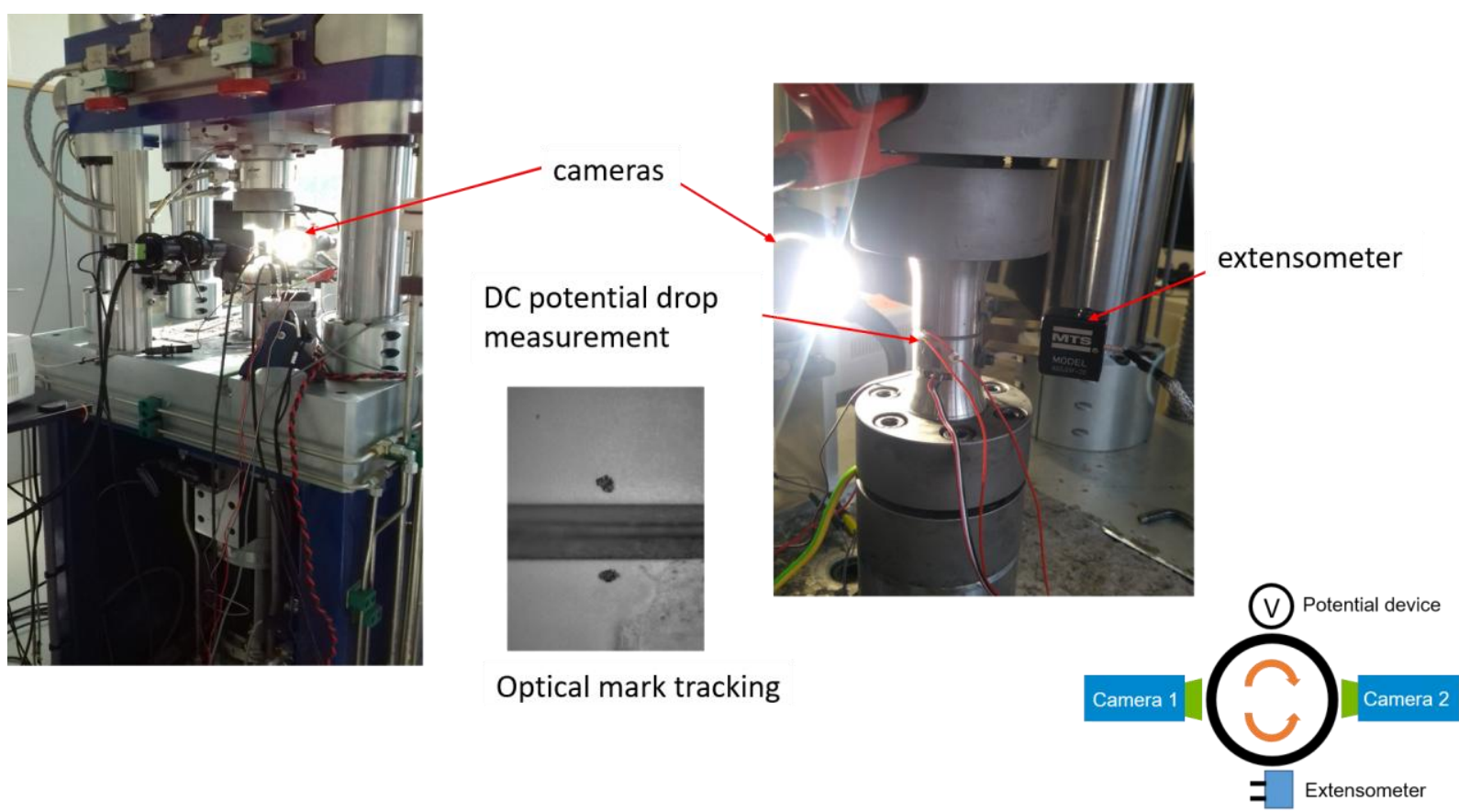

Figure 3 : Specimen mounted on the testing machine and equiped with a mechanical and two optical extensometers, plus a DC potential drop device, at four angular positions along the periphery

Two series of fully-reversed push-pull tests were performed, with or without a superimposed torque: one at $\pm 85 \mathrm{kN}$ with a frequency of $0.5 \mathrm{~Hz}$, and one at $\pm 68 \mathrm{kN}$ with a frequency of $1 \mathrm{~Hz}$. The test conditions are indicated in Table 2, as well as the number of cycles until complete fracture, normalized by that of the specimen broken in pure mode I at the same axial loading range. Due to a slight coupling between the tensile and torsional actuators, the torque was not perfectly steady, but exhibited small fluctuations, in phase with the tensile loading, around the mean value. The potential effects of this imperfection will be discussed below. Note however that in many engineering applications, the torque on the rotating shaft is not perfectly static, due for example to torsional vibrations or hydrodynamic effects, which induce small fluctuations of $\mathrm{K}_{\mathrm{III}}$ around a non-zero mean value.

Analytical expressions of $\mathrm{K}_{\mathrm{I}}$ and $\mathrm{K}_{\mathrm{III}}$ for a circular crack are available in the handbook of Tada \& Paris [30]. Using these expressions, the expected evolutions with crack depth of the mode mixity ratio $\mathrm{K}_{\text {IIImean }} / \mathrm{K}_{\text {Imax }}$ during the tests were computed, neglecting the torque fluctuations. As it can be seen on Fig. $4 \mathrm{a}$, because $\mathrm{K}_{\mathrm{III}}$ rises much faster than $\mathrm{K}_{\mathrm{I}}$, the mode mixity ratio is expected to double approximately during a test. Besides, the torque fluctuations induce a rising $\Delta \mathrm{K}_{\mathrm{III}}$, as illustrated on Fig $4 \mathrm{~b}$, which shows the expected evolution of $\Delta \mathrm{K}_{\mathrm{III}}$, for the smallest and largest torque fluctuations (namely $\pm 6.1 \mathrm{Nm}$ for test $\# 14$ and $\pm 15.5 \mathrm{Nm}$ for test \#18). $\Delta \mathrm{K}_{\mathrm{III}}$ is initially less than $0.5 \mathrm{MPa} \sqrt{\mathrm{m}}$, and should reach 2 to $4 \mathrm{MPa} \sqrt{\mathrm{m}}$ at the end of stable fatigue crack growth, depending on the amplitude of the torque fluctuations. Note however that these values do not take into account crack face contact and friction (especially during the compressive stage of the cycle), and are thus certainly overestimated. Should the crack remain locked by friction during compression, the effective $\Delta \mathrm{K}_{\mathrm{III}}$ would be only half these values, and would probably have a negligible impact. 


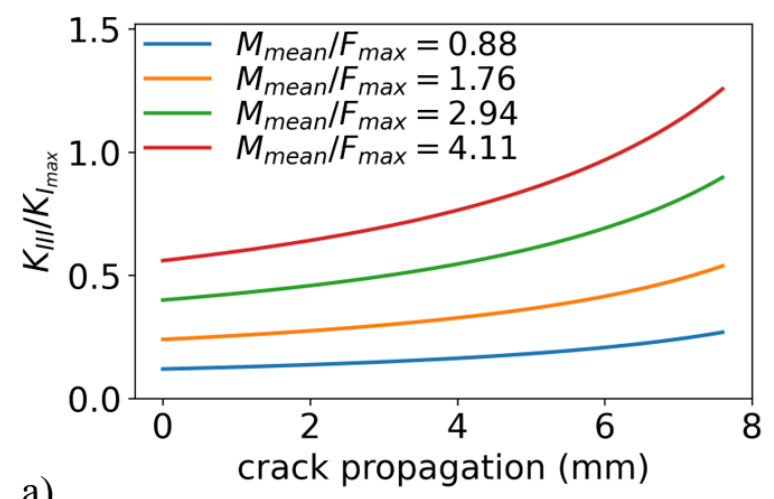

a)

crack propagation $(\mathrm{mm})$

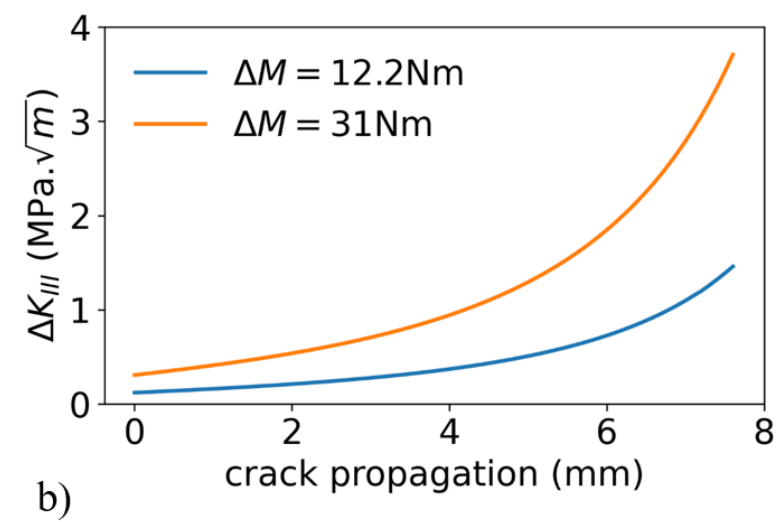

b)

Figure 4 : a) expected evolution with crack depth of the mode mixity ratio at $\mathrm{K}_{\text {Imax }}$, for a circular concentric crack, neglecting torque fluctuations, and b) expected evolution of $\Delta \mathrm{K}_{\mathrm{III}}$ for the smallest and largest torque fluctuations among the tests (namely $\pm 6.1 \mathrm{Nm}$ for test \#14 and \pm $15.5 \mathrm{Nm}$ for test \#18)

A beach marking technique was used to track the shape and position of the crack front at different stages of propagation. To do so, the peak load was kept unchanged, but the $\mathrm{R}$ ratio was increased to 0.5 during a few thousand cycles, whose number was adjusted, so as to induce just enough crack growth to produce detectable beach marks. No transient after-effect of these marking blocks on the subsequent evolutions of the potential drop or compliance recorded upon resumption of the normal loading was noticed. This was reassuring in relation to any possible disruption of crack growth.

\begin{tabular}{|c|c|c|c|c|c|c|c|}
\hline Test & $\begin{array}{l}\text { Axial } \\
\text { load F }\end{array}$ & $\begin{array}{c}\text { Initial } \\
\Delta \mathrm{K}_{\mathrm{I}} \\
\mathrm{MPa} \sqrt{\mathrm{m}}\end{array}$ & $\begin{array}{l}\text { Torsion } \\
\mathrm{M}_{\text {mean }} \pm \\
0.5 \Delta \mathrm{M}\end{array}$ & $\begin{array}{c}\text { Initial } \\
\mathrm{K}_{\mathrm{III}} \\
\mathrm{MPa} \sqrt{\mathrm{m}}\end{array}$ & $\begin{array}{l}\text { Initial } \\
\mathrm{K}_{\mathrm{III} /} \mathrm{K}_{\mathrm{I}}\end{array}$ & $\begin{array}{c}\text { Number } \\
\text { of cycles } \\
\text { to failure } \\
\mathrm{N}\end{array}$ & $\begin{array}{l}\text { Relative } \\
\text { number of } \\
\text { cycles to } \\
\text { failure } \\
\mathrm{N}_{\mathrm{N}}\end{array}$ \\
\hline \#13 & $\pm 68 \mathrm{kN}$ & 10.4 & 0 & 0 & 0 & 269813 & 1 \\
\hline$\# 14$ & $\pm 68 \mathrm{kN}$ & 10.4 & $60 \pm 6.1 \mathrm{Nm}$ & 1.3 & 0,125 & 165163 & 0.61 \\
\hline \#18 & $\pm 68 \mathrm{kN}$ & 10.4 & $\begin{array}{c}120 \pm 15.5 \\
\mathrm{Nm}\end{array}$ & 2.6 & 0,25 & 247147 & 0.92 \\
\hline \#7 & $\pm 85 \mathrm{kN}$ & 13 & 0 & 0 & 0 & 142841 & 1 \\
\hline$\# 10$ & $\pm 85 \mathrm{kN}$ & 13 & $\begin{array}{c}150 \pm 12.6 \\
\mathrm{Nm}\end{array}$ & 3.2 & 0,25 & 214283 & 1.5 \\
\hline \#8 & $\pm 85 \mathrm{kN}$ & 13 & $\begin{array}{c}250 \pm 14.2 \\
\mathrm{Nm}\end{array}$ & 5.3 & 0,41 & 195483 & 1.37 \\
\hline \#9 & $\pm 85 \mathrm{kN}$ & 13 & $\begin{array}{c}350 \pm 11.2 \\
\mathrm{Nm}\end{array}$ & 7.4 & 0,57 & 158260 & 1.11 \\
\hline
\end{tabular}

Table 2: Loading conditions and number of cycles to fracture 
The load (F) - COD curves were used to measure the compliance of the specimen so as to deduce the crack length, but also to assess crack closure, namely $K_{\text {Iclosure, }} \Delta \mathrm{K}_{\mathrm{I}}^{\text {eff }}=\mathrm{K}_{\text {Imax }}-$ $K_{\text {Iclosure }}$ and $U=\Delta K_{I}{ }^{\text {eff }} / \Delta K_{I}{ }^{\text {nom }}$, with the method described in ASTM E 467-08 standard [31]. An affine regression $(\mathrm{COD}=\mathrm{aF}+\mathrm{b})$ is done at the beginning of the unloading stage, when the crack is completely opened (between $\mathrm{F}_{\max }$ and $0.75 \mathrm{~F}_{\max }$ ) and the slope, a, corresponds to the compliance. Then, the load is replotted versus the "corrected opening displacement" $\delta=\mathrm{COD}$ $(\mathrm{aF}+\mathrm{b})$, or in other words, the deviation from a linear unloading. Finally, $\mathrm{K}_{\text {Iclosure }}$ is conventionally defined as the value of $\mathrm{K}_{\mathrm{I}}$ when the deviation reaches $2 \%$ of the maximum $\delta$.

The crack paths (crack front shape and position after precracking, after each marker block or just before unstable fracture, crack face roughness, local crack twisting angle...) were documented by SEM or optical observations, as well as by topographic measurements. Qualitative mesoscale topographic images of each fracture surface were obtained using a Keyence numerical optical microscope. A more accurate topographic characterization of the fracture surfaces was performed using an optical profilometer (Wyko NT9800), with an in-plane resolution of $7.4 \mu \mathrm{m}$ and an out of plane resolution of $3 \mathrm{~nm}$. Only the part of the fracture surfaces corresponding to fatigue crack growth was considered, excluding the ductile fracture zone. Because a random noise was observed in the measured height signal, several types of filters were tried (low-pass, median, averaging over different window sizes...) to reduce it, without significant differences in the results, so that a moving average over a 9x9 pixels $(66 * 66$ $\mu \mathrm{m}$ ) window was finally adopted. Series of 1.5 to $2.5 \mathrm{~mm}$ long orthoradial profiles more or less normal to the crack propagation direction were then extracted, at various radial and angular positions (see Fig. 10b, below).

Each of these profiles was analysed to extract the local crack roughness and twist angles. The roughness was characterized by the parameter $\mathrm{Ra}$, defined as the arithmetical mean height relative to the center line of the profile. The latter was obtained by substracting the height offset and average tilt of the raw profile. Since the same averaging procedure was applied to all specimens, it could not bias the comparison of the roughness of specimens broken in pure mode I or mode I + various superimposed static torques. The local twist angles correspond to the downwards slopes of the raw profiles, because these facets undergo a torque-induced opening stress (while the upward slopes correspond to facets that undergo a torque-induced compression). The purpose was to compare the measured twist angles with those predicted by a bifurcation criterion issued from Linear Elastic Fracture Mechanics. Note that such an approach considers a crack in an homogeneous medium, and does not consider the microstructure-scale roughness that the averaging treatment mentioned above might suppress $(66 \mu \mathrm{m}$ corresponds approximately to the size of two former austenite grains).

\section{Results and analysis}

The normalized fatigue lives reported in the last column of Table 2 show that contrary to what was expected from the literature, the presence of a torque did not systematically delay fatigue fracture. It was indeed the case for the highest axial loading range, but life was enhanced by $50 \%$ at most, while for the smallest axial loading range, life was reduced by up to $40 \%$ by a superimposed torque. These results are analyzed below based on fractographic observations, measurements of crack closure effects and elastic-plastic simulations. 


\section{IV.1. Crack paths}

\section{Crack front shapes}

Figure 5 shows optical images of all fracture surfaces, on which the positions of the extensometer, cameras and DC potential drop measurements along the outer surface are also indicated. Some crack front markings are readily visible, and some faint ones could only be detected under the microscope. All were underlined in color. For the highest torques, (tests \#8 and \#9, during which exactly the same marker blocks as during test \#7 had been applied), the front markings could not even be detected under the microscope, since it had been erased by crack face friction.
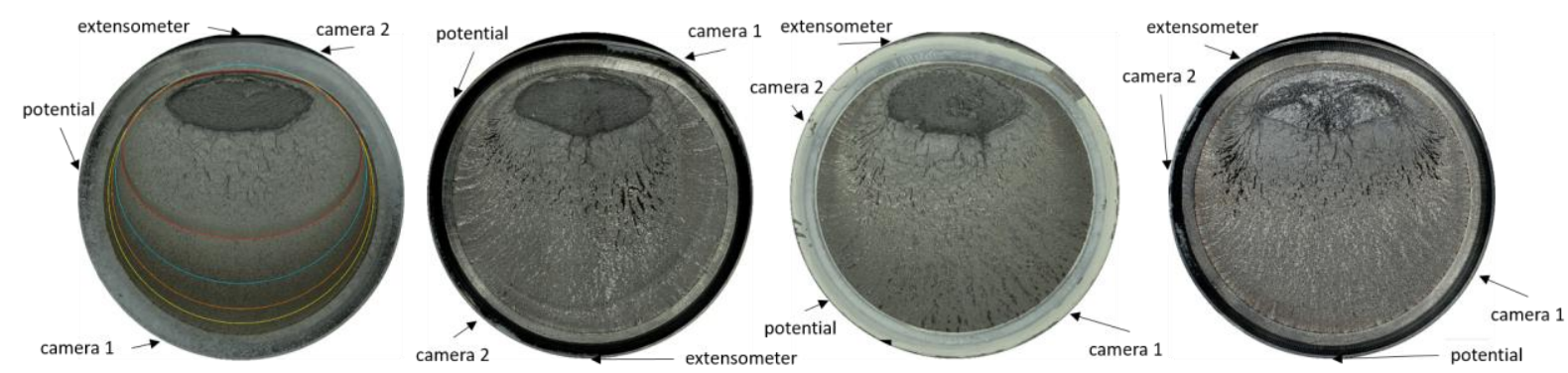

a) Test $\# 7, \pm 85 \mathrm{KN}$

b) Test $\# 10, \pm 85 \mathrm{KN}, 150 \pm 11.5 \mathrm{Nm}$ c) Test $\# 8, \pm 85 \mathrm{KN}, 250 \pm 14 \mathrm{Nm}$

d) Test $\# 9, \pm 85 \mathrm{KN}, 350 \pm 11.2 \mathrm{Nm}$
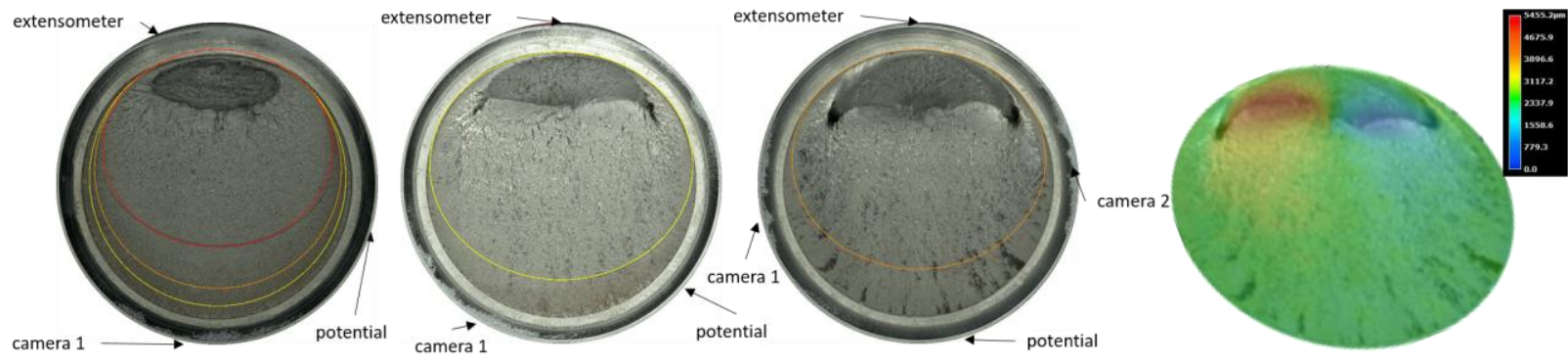

e) Test \#13, $\pm 68 \mathrm{KN}$

f) Test \#14, $\pm 68 \mathrm{KN}, 60 \pm 6.1 \mathrm{Nm}$ g) Test $\# 18, \pm 68 \mathrm{KN}, 120 \pm 15.5 \mathrm{Nm}$ h) Test $\# 18, \pm 68 \mathrm{KN}, 120 \pm 15.5 \mathrm{Nm}$

Figure $5:$ (a-g) Optical images of the fracture surfaces. The colored ellipses indicate crack front markings. The positions of the extensometer, cameras and DC potential drop measurements are indicated. h) Topographic image of specimen \#18

More and more eccentric, less and less circular cracks are observed. Torsional loading had a limited effect on the shape and dimensions of the final fatigue crack front (just before unstable fracture, which is outside the scope of this paper) for the tests run in mode I + III with an axial load of $\pm 85 \mathrm{kN}$, for which no macro-scale deviation from the plane normal to the tensile axis is observed. By contrast, for tests \#14 and \#18 run in mode I + III with an axial load of $\pm 68 \mathrm{kN}$, the final crack front shape deviates significantly from the quasi-ellipse observed in all other cases, and a macroscale crack twisting is revealed by qualitative topographic images captured with the numerical optical microscope (Fig. 5h).

The origin of the systematic eccentric crack growth, which could not be avoided, despite many efforts to improve the alignment during specimen mounting was quite probably a concentricity defect of the notch, whose geometry after machining was initially not in accordance with the specifications. Observations of the specimens with a digital microscope at low magnification -allowing diametrically opposed notch roots and free surfaces to be observed simultaneously- showed that machining resumption to correct this error had induced up to 150$200 \mu \mathrm{m}$ eccentricity.

This eccentric crack growth explains why the compliance evolution measured at different angular positions are quite different: it increases in the angular sector where crack growth is 
enhanced by the bending stresses, and remains constant until it finally decreases, in the sector where crack growth is hindered by bending-induced compression (Figure 6).

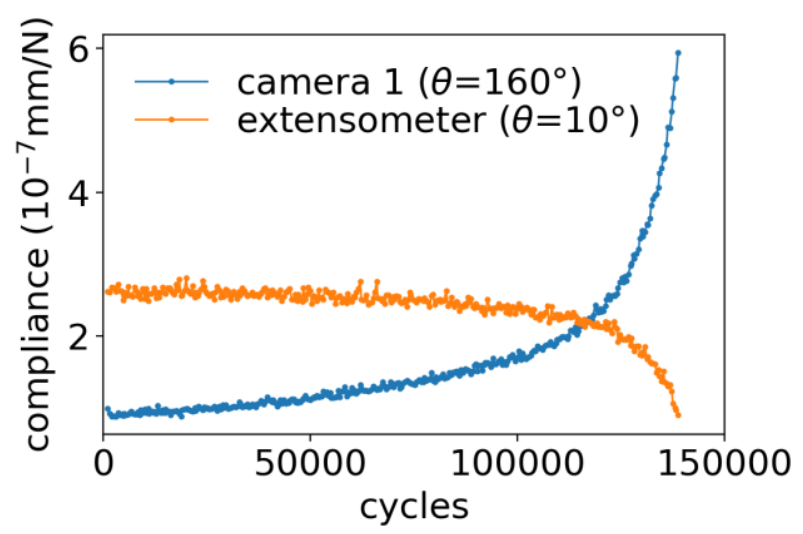

Figure 6: Evolution of the compliance measured at two angular positions during test \#7

It will be shown below that these evolutions can be retrieved approximately if the eccentric evolution of the crack shape is taken into account, and that the test data do not have to be discarded, even though their analysis requires extra modelling efforts.

$3 D$ Finite element model for the computation of the apparent compliance, potential drop and stress intensity factors all along the eccentric, nearly elliptical crack fronts

For a concentric circular crack in a round bar, analytical expressions of $\mathrm{K}_{\mathrm{I}}$ and $\mathrm{K}_{\mathrm{III}}$ as a function of the crack depth, axial load and torque are available, as mentioned above [30]. Besides, it is easy to calibrate numerically or analytically extensometers, in order to deduce the crack depth from the measured variation of compliance [32] or a DC potential drop device, to deduce the crack depth from the measured variation of the electric potential drop [29].

The growth of perfectly centered and circular cracks is quite difficult to obtain in circumferentially notched cylindrical specimens submitted to monotonic or cyclic tension, since any initial imperfection in the notch or precrack concentricity, or a very slight misalignement of the sample and loading axis induce bending and, as a result a more and more eccentric, elliptical crack. This has been analyzed in detail by several authors [33-34], but only for tensile loading. The authors show that the bending stresses due to crack eccentricity increase $K_{I}$ on the side where the crack is deepest and reduce it on the side where it is shallowest, where contact between the upper and lower crack lips occurs prematurely. To the best of our knowledge, mixed-mode loading along the front of an eccentric, non-circular crack in a shaft submitted to rotating bending and torsion was analyzed only in [11].

A 3D finite element model was thus developed to compute the stress intensity factors (SIF) $\mathrm{K}_{\mathrm{I}}, \mathrm{K}_{\mathrm{II}}$ and $\mathrm{K}_{\mathrm{III}}$ along the front of an elliptical and eccentric crack, in a cylinder loaded in tension and torsion, as illustrated by Figure 7. The axes of the elliptical front are denoted by X and Y. X is the direction along which the crack is shifted. The upper and lower volumes of the cylinder are symmetric with respect to X-Y crack plane. Eight nodes hexahedrons linear elements are used for the mesh, which is refined to $40 \mu \mathrm{m}$ near the crack front. A uniform tension load and a linearly varying shear stress are applied on the upper surface, while the lower surface of the 
cylinder is blocked in the three directions. Unilateral contact conditions are imposed between the two crack surfaces. Any position along the front is referred below by its angle $\theta$, relative to the position of minimum crack growth. The local crack depth, $a(\theta)$, defined on Figure 7 , corresponds to the distance from the crack front to the notch root along the direction normal to the front. The point of maximum crack growth is diametrically opposed, and thus corresponds to an angle of $180^{\circ}$.
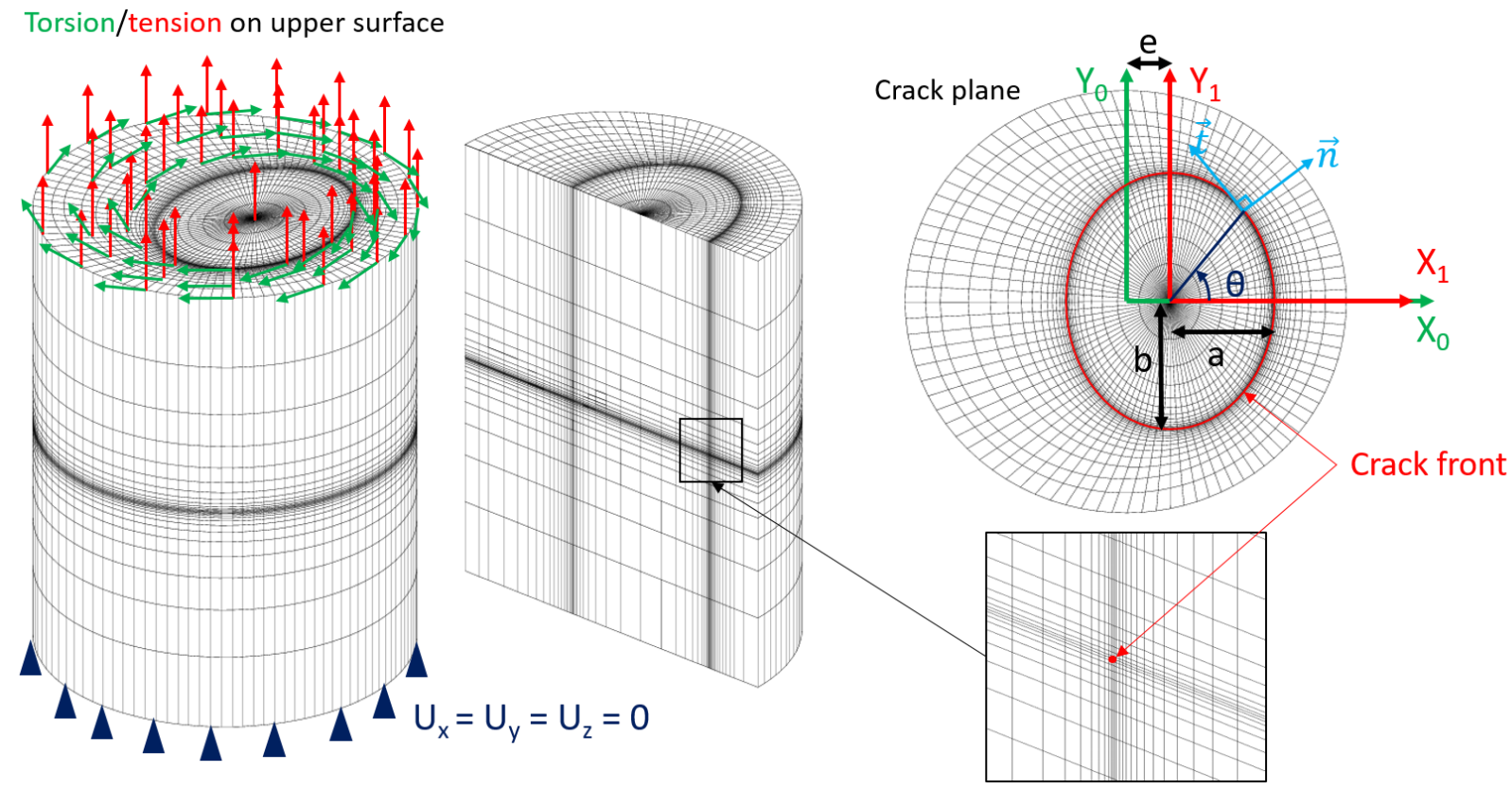

Figure 7: Finite element model developed to compute the SIFs along the front of an eccentric, non-circular crack in a cylindrical specimen loaded in tension and torsion

The mesh was designed with lines normal to the crack front (direction $\vec{n}$ on fig 7 , while direction $\vec{t}$ is tangent to the front), which allows plots along these lines of the relative crack opening displacement (COD) or the two components of the relative crack sliding displacements : $\mathrm{CSD}_{\mathrm{II}}$ and $\mathrm{CSD}_{\mathrm{III}}$, respectively normal and parallel to the crack front, versus the square root distance $(\mathrm{Vr})$ from the crack front. According to linear elastic fracture mechanics:

$$
\begin{gathered}
C O D=U_{z}(r, \pi)-U_{z}(r,-\pi)=8 \frac{K_{I} \sqrt{r}}{E \sqrt{2 \pi}}\left(1-v^{2}\right) \\
C S D_{I I}=U_{n}(r, \pi)-U_{n}(r,-\pi)=8 \frac{K_{I I} \sqrt{r}}{E \sqrt{2 \pi}}\left(1-v^{2}\right) \\
C S D_{I I I}=U_{t}(r, \pi)-U_{t}(r,-\pi)=8 \frac{K_{I I I} \sqrt{r}}{E \sqrt{2 \pi}}(1+v)
\end{gathered}
$$

so that a linear regression over the first few nodes from the crack front yields a slope which is directly proportional to $\mathrm{K}_{\mathrm{I}}, \mathrm{K}_{\mathrm{II}}$ or $\mathrm{K}_{\mathrm{III}}$. To validate the model and computation procedure, simulations were run for perfectly centered and circular crack fronts, and the SIFs from the analytical expressions of Tada \& Paris [30] were retrieved within 3\% error at most.

As an example, the computed values of $\mathrm{K}_{\mathrm{I}}, \mathrm{K}_{\mathrm{II}}$, and $\mathrm{K}_{\mathrm{III}}$ at a few points along the front of an eccentric, elliptical crack for $\mathrm{F}=85 \mathrm{kN}$ and $\mathrm{M}=250 \mathrm{Nm}$ are indicated on Figure $8 \mathrm{a}$. $\mathrm{K}_{\mathrm{I}}$ is maximum at $\theta=180^{\circ}$, where the crack is deepest, and minimum at the diametrically-opposed point $(\theta=0)$. For a higher crack eccentricity, the minimum $K_{I}$ at $\theta=0^{\circ}$ drops to zero, as also reported by Toribio et al. [34]. The peak values of $\mathrm{K}_{\mathrm{III}}$ are found for $\theta$ around $95^{\circ}$ and $265^{\circ}$. $\mathrm{K}_{\mathrm{II}}$ is not zero, but remains small compared to $\mathrm{K}_{\mathrm{III}}$, and exhibits a nearly skew-symmetric angular 
profile, and reaches its peak values where the crack front deviates most from the orthoradial direction, at $112^{\circ}$ and $248^{\circ}$ for this example. Figure $8 \mathrm{~b}$, c, and $\mathrm{d}$ compare respectively the evolutions of $\mathrm{K}_{\mathrm{I}}, \mathrm{K}_{\mathrm{III}}$ and $\mathrm{K}_{\mathrm{III}} / \mathrm{K}_{\mathrm{I}}$ expected for a centered and circular crack to those computed with the FE model at various angular positions along the front, at various stages of test \#8 (the way the successive positions and shapes of the front were retrieved will be explained later). In the angular sector where crack growth is assisted by bending-induced tension $\left(90\right.$ to $\left.180^{\circ}\right)$, the mode mixity ratio is lower than expected, while it is much larger than expected in the sector where bending-induced compression reduces $\mathrm{K}_{\mathrm{I}}$ and thus hinders crack growth.
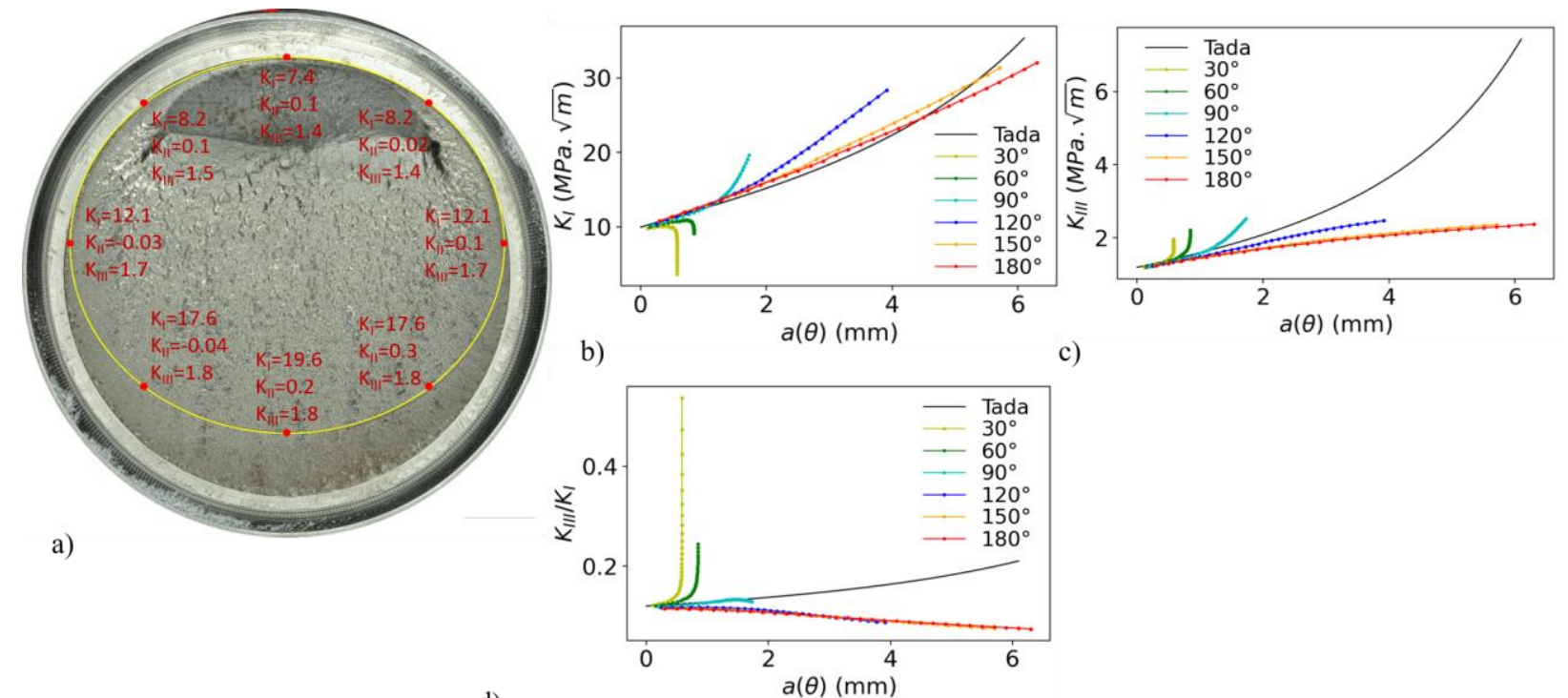

c)

d)

Figure 8: Example of computed SIFs for $\mathrm{F}=68 \mathrm{kN}$ and $\mathrm{M}=60 \mathrm{Nm}$, a) values of $\mathrm{K}_{\mathrm{I}}, \mathrm{K}_{\mathrm{II}}$, and $\mathrm{K}_{\mathrm{III}}$ (in $\mathrm{MPa} \sqrt{\mathrm{m}}$ ) at a few points along the front of an eccentric, elliptical crack b-d) computed evolutions of $\mathrm{K}_{\mathrm{I}}, \mathrm{K}_{\mathrm{III}}$ and the mode mixity ratio $\mathrm{K}_{\mathrm{III}} / \mathrm{K}_{\mathrm{I}}$

\section{Microscopic aspects of the crack paths}

As mentioned above, most of the crack front markings had been erased by crack face repeated contacts in the specimens submitted to mode I + III loadings. Crack face mating can already be expected during fully reversed push-pull loading alone, but in the present case, it was not sufficient to erase the crack front markings in specimens \#7 and \#13 loaded in pure mode I. This phenomenon was enhanced thus by the permanent shift of crack face asperities induced by a static torque.

Under the optical microscope the fracture surfaces of the specimens submitted to mode I + III loadings, exhibit shiny traces, parallel to the (more or less radial) local crack growth direction that the two specimens broken in pure mode I do not show. A zoom on those traces reveals up to hundreds of microns-long quasi-tangential rubbing marks (Figure 9a-b). However, the fracture surfaces were not covered with wear debris, which suggests either a ductile shearing of the metal without fracture of the asperities, and thus generating few debris, or that the rubbing marks formed late in the fatigue life, so that the number of remaining cycles was too low to generate much debris. This will be discussed later.

In these specimens, SEM observations of the area corresponding to the final stage of fatigue crack growth (last few millimeters before unstable fracture) reveal the presence of twisted facets, whose side submitted to torque-induced compression is heavily worn, while the opposite side, 
submitted to torque-induced tension is intact and exhibits widely spaced striations typical of fast mode I crack growth (Fig. 9c). However, it is important to note that in the SEM, the samples broken in pure mode I also exhibit twisted facets in the area corresponding to the final stage of fatigue crack growth, and heavy wear marks on the crests of the highest reliefs running parallel to the crack growth direction, although without the asymmetry between worn or intact facets associated with the presence of a torque.

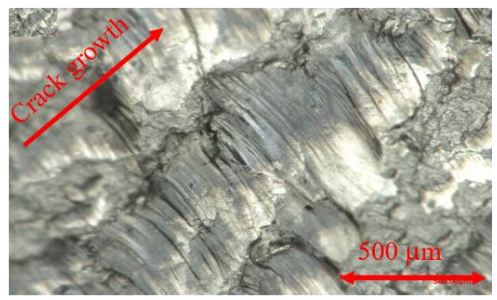

a) Test \#14, $\pm 68 \mathrm{KN}, 60 \pm 6.1 \mathrm{Nm}$

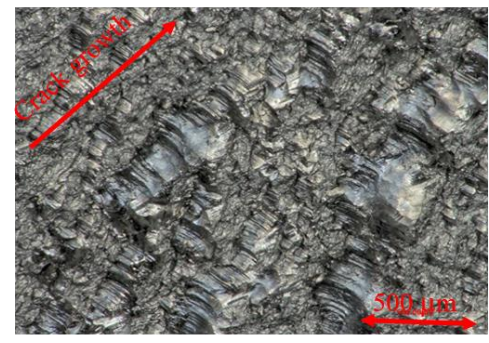

b) Test \#8, $\pm 85 \mathrm{KN}, 250 \pm 14.2 \mathrm{Nm}$
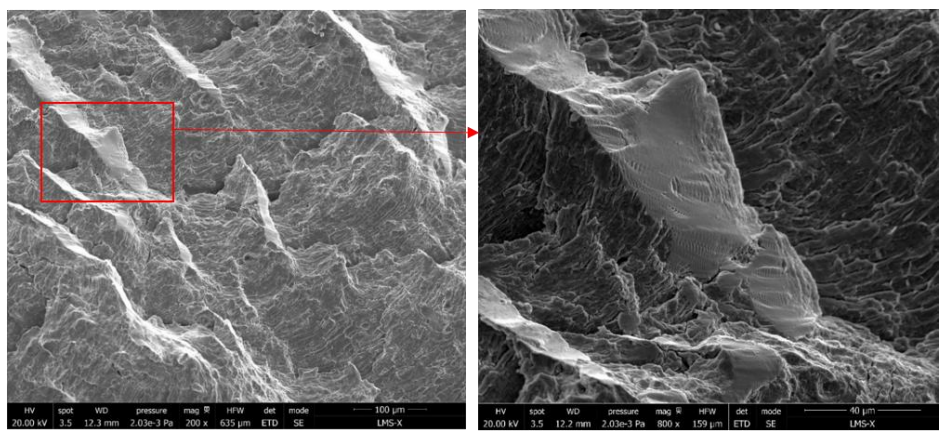

c)

Test $\# 10, \pm 85 \mathrm{KN}, 150 \pm 11.5 \mathrm{Nm}$
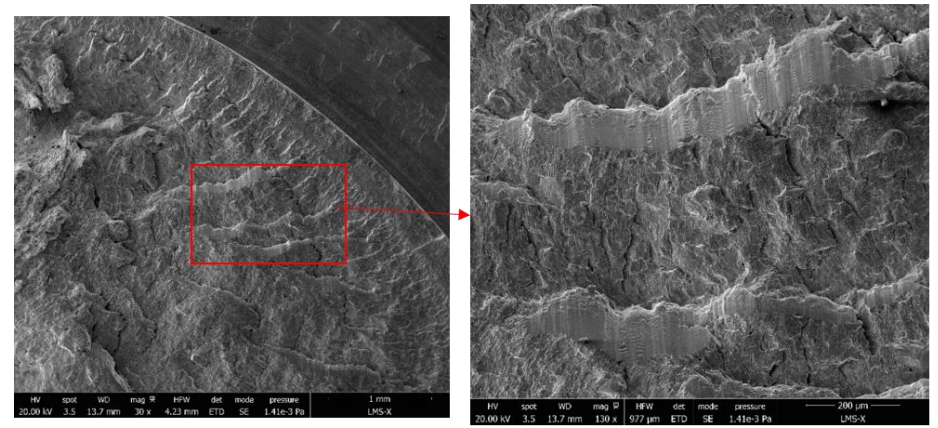

d)

Test \#13, $\pm 68 \mathrm{KN}$

Figure $9: a-b)$ Shiny traces along the local crack growth direction, covered with transverse abrasion marks observed with the optical microscope, c-d) SEM images of twisted and worn facets

Figure 10a shows an example of optical profilometry on sample \#8. Series of tangential height profiles were extracted at various radial (a) and angular positions ( $\theta$ ) (Fig. 10b). The local roughness $R_{a}(a, \theta)$, and local twist angle $\phi(a, \theta)$ were then deduced. Even though crack twisting was not expected in that case, the same type of measurements was made on the specimens broken in mode I, for comparison. No qualitative difference in the aspect of the tangential height profiles between mode I + III and mode I was observed, and in particular no torque-induced asymmetry (see Fig. 10c). 

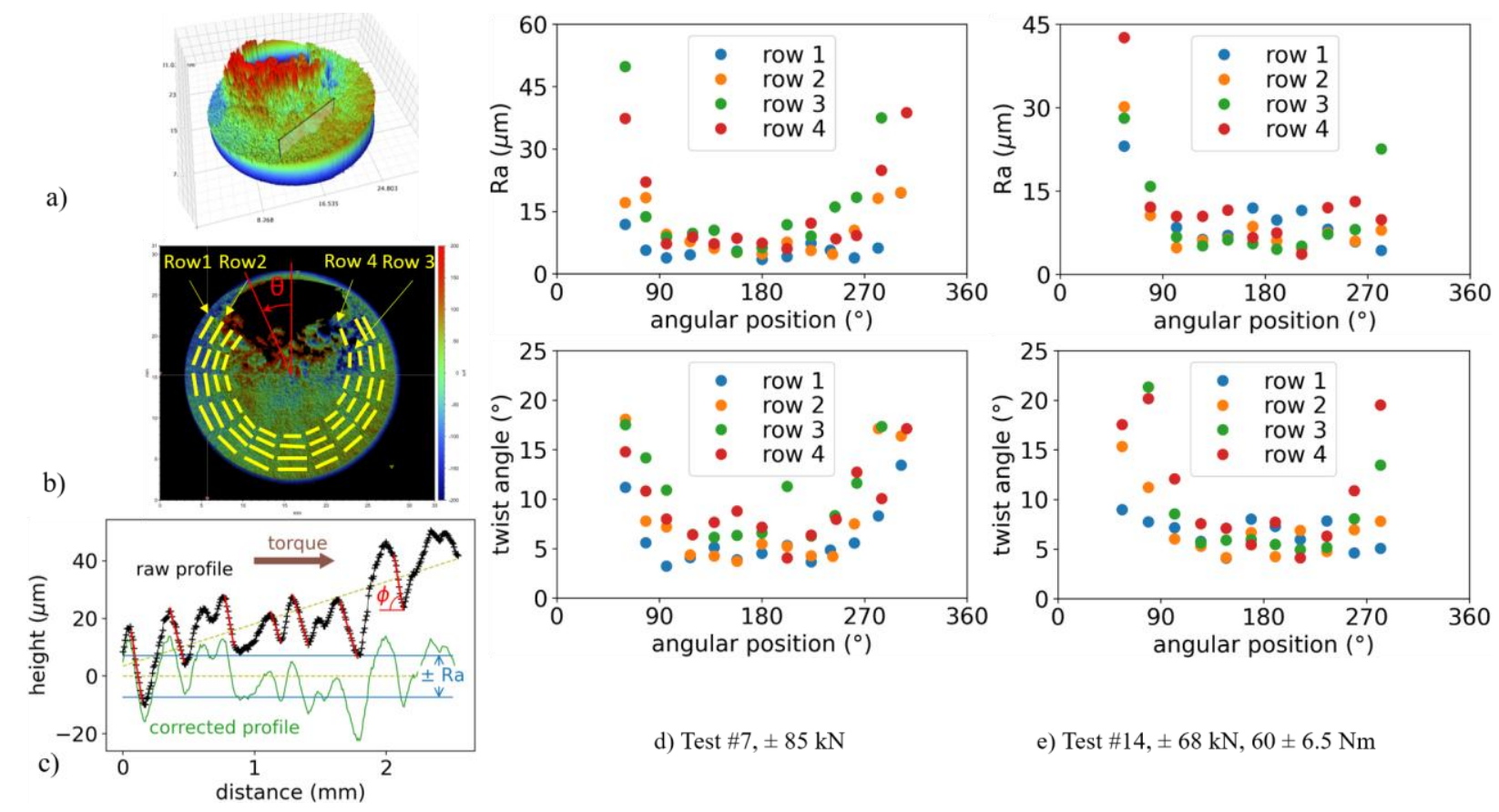

d) Test \#7, $\pm 85 \mathrm{kN}$

e) Test \#14, $\pm 68 \mathrm{kN}, 60 \pm 6.5 \mathrm{Nm}$

Figure 10: Topographic measurements on fracture surfaces. a) example of measured topography b) notations for the tangential sections, c) examples of tangential height profiles (the arrow indicates the direction of the static torque), d-e) roughness and twist angles measured for d) test \#7 ( $\pm 85 \mathrm{kN})$ and e) test \#14, ( $\pm 68 \mathrm{kN}, 60 \pm 6.5 \mathrm{Nm})$

Figure 10d and e show the measured crack face roughness and twist angles as a function of the angular positions, for tests \#14 $( \pm 68 \mathrm{kN}, 60 \mathrm{Nm})$ and \#7 $( \pm 85 \mathrm{kN})$, respectively. In mode I as well as in mode I + III, the crack face roughness and the twist angles rise in the angular sector where the crack hardly grows. No significant difference in crack face roughness associated with the presence of mode III was found.

Figure 11 compares the measured evolutions of the local twist angle with that predicted by the MTS criterion (equation 1), based on the local mode mixity ratios at peak axial load, computed with the finite element model described above. The local twist angle remains much smaller than predicted by the MTS criterion, as also reported for several materials by Hourlier and Pineau [13-14]. Furthermore, in the present case, the twist angle does not even correlate with the local mode-mixity ratio. This point will be discussed below.
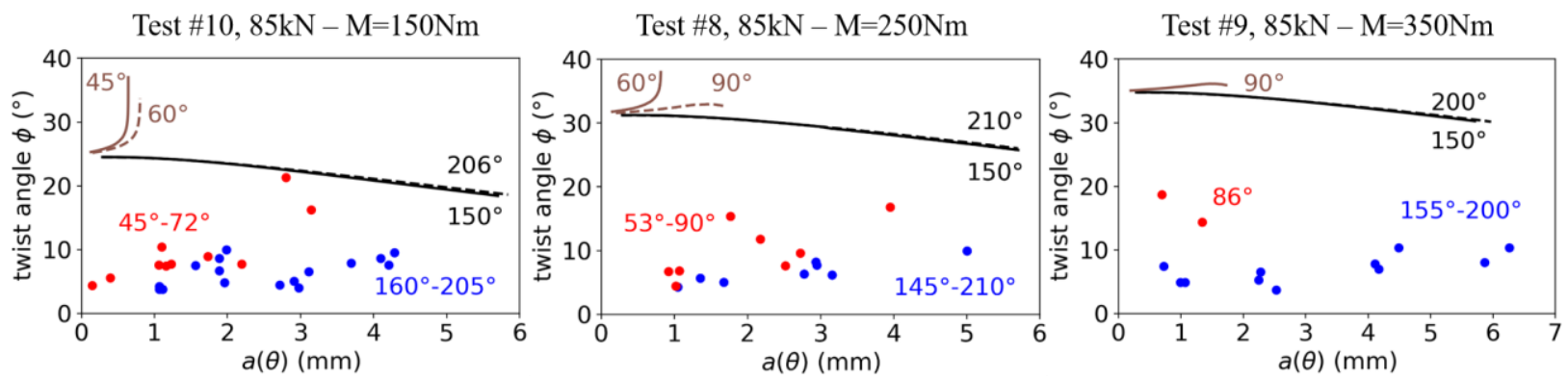

Figure 11: Comparison of the measured local twist angles (dots) with those predicted by the MTS criterion (curves), based on the local mode mixity ratios.

\section{IV.2. Crack closure effects and ratchetting rise of the crack sliding displacement}




\section{Experimental observations}

Figure 12a-c shows typical examples of axial load-crack opening displacement (COD) curves measured by two cameras and an extensometer at three different angular positions (denoted by $\theta)$ along the specimen surface, at various stages of crack growth, for test $\# 10( \pm 85 \mathrm{kN}, 150 \pm$ $11.6 \mathrm{Nm})$.

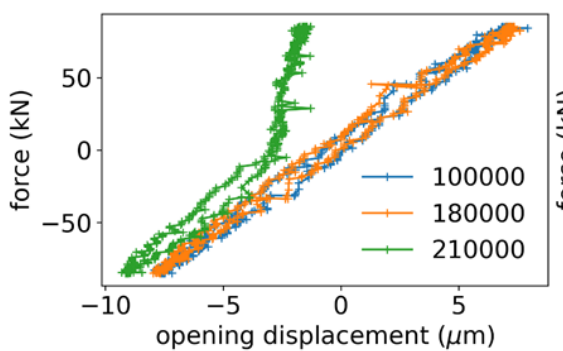

a) camera $1\left(\theta=40^{\circ}\right)$

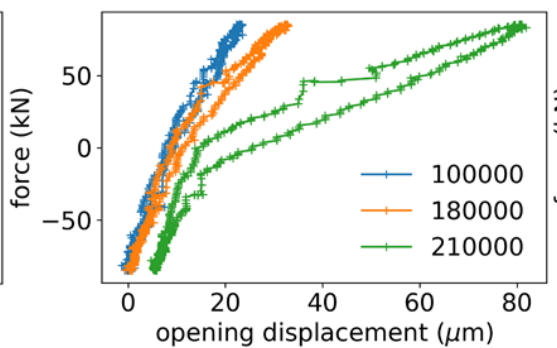

b) camera $2\left(\theta=140^{\circ}\right)$

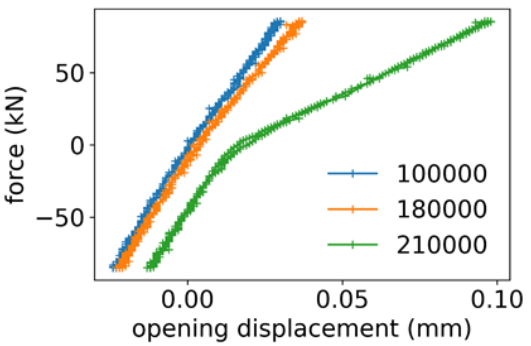

c) extensometer $\left(\theta=180^{\circ}\right)$
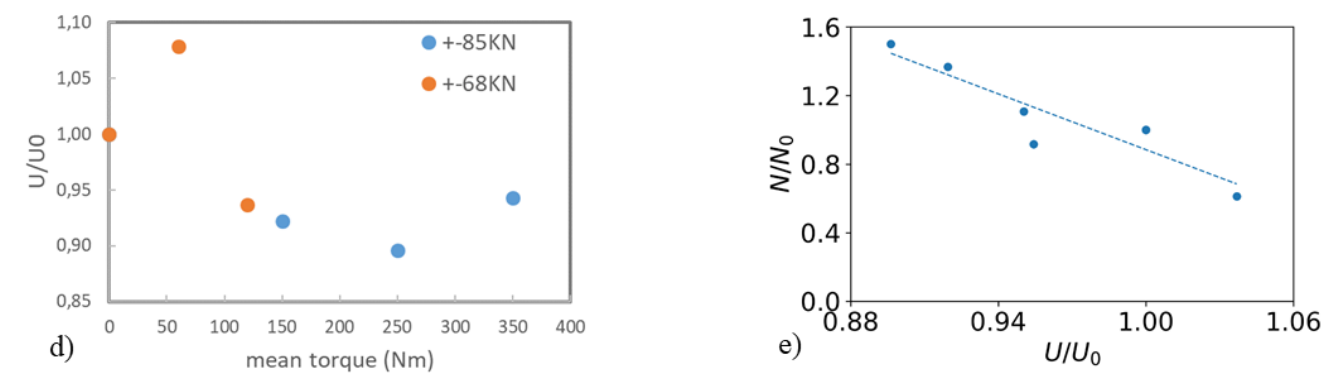

Figure 12: a-c) Load - COD curves measured at different angular positions and various stages of test \#10 $( \pm 85 \mathrm{kN}, 150 \pm 11.6 \mathrm{Nm})$, d) Influence of the mean torque on the mean normalized $\mathrm{U}=\Delta \mathrm{K}_{\mathrm{I}}^{\text {eff }} / \Delta \mathrm{K}_{\mathrm{I}}^{\text {nom }}$, and e) correlation between the effect of the torque on the fatigue life and its effect on $U$.

The width of the loops (in other words, the opening amplitude, $\triangle \mathrm{COD}$ ) increases with the number of cycles at $\theta=140^{\circ}$ and $180^{\circ}$, that is in the angular sector where crack growth is favored by bending-induced tensile stresses, while it decreases at $\theta=40^{\circ}$, in the angular sector where crack growth is hindered by bending-induced compressive stresses. At the latter position, the apparent stiffness becomes higher in tension than in compression at 210000 cycles, because at that late stage, the crack faces come into contact as soon as tension is applied to the specimen. By contrast, during the same cycle, at $\theta=140^{\circ}$, the increase in slope indicative of crack closure upon unloading clearly occurs when the applied load is already compressive, which suggests that at that place, $U=\Delta K_{I}{ }^{e f f} / \Delta K_{I}^{\text {nom }}$ is larger than 1 . It is also the case at $\theta=180^{\circ}$, but due to the larger gage length of the extensometer $(12 \mathrm{~mm}$, instead of 1.5 to $2 \mathrm{~mm}$ for the optical measurements) its signal is less sensitive to local non-linearities, like crack closure. For a given angular position, the value of $U=\Delta K_{I}{ }^{\text {eff }} / \Delta K_{I}{ }^{\text {nom }}$ deduced from the load-COD loops reached a steady-state, beyond the first millimeter of local crack growth, within the accuracy of the measurements.

It is thus this steady-state value, measured by the camera located in the angular sector where crack growth was fastest which, after normalization by the value measured in pure mode I at the same axial loading range, is plotted versus the mean torque $\mathrm{M}_{\text {mean }}$ on Figure $12 \mathrm{~d}$. Except for one case (test \#14), the presence of the torque reduced the effective fraction of $\Delta \mathrm{K}_{\mathrm{I}}$, but to a relatively small extent $(10 \%$ at most), and, beyond $250 \mathrm{Nm}$, the reduction did not seem to increase any more.

Figure 12e shows the number of cycles to failure in mode I + III, N, normalized by the number of cycles to failure in pure mode $\mathrm{I}$ for the same axial loading range (denoted as $\mathrm{N}_{0}$ ) 
versus the ratio of $\mathrm{U}$ in mode $\mathrm{I}+\mathrm{III}$ normalized by $\mathrm{U}_{0}$, in pure mode $\mathrm{I}$. The observed linear correlation shows that the effect of the torque on the fatigue life of the specimens is mostly a consequence of its effect on crack closure.

Figure 13 shows examples of axial load - tangential crack sliding displacement (CSD) and torque - CSD loops measured at various stages of test $\# 10( \pm 85 \mathrm{kN}, \mathrm{M}=150 \pm 11.6 \mathrm{Nm})$. During this test, as well as during all other tests in mode I + III, nearly no sliding displacement was observed during the compressive stage of the cycles, probably because of crack face locking, but during the tensile stage, more and more sliding displacement occurred. These oscillations of the tangential crack sliding displacement are consistent with the presence of tangential wear marks on the fracture surfaces. However, their amplitude during a cycle (just a few microns measured on the outer surface where the CSD is maximum) is nearly hundred times smaller than the length of the wear marks shown on Fig. $9 a$ and $b$.

Furthermore, a progressive shift of the loops, or in other words: a rise in the mean sliding displacement was observed in the same direction as that of the mean torque. Figure $13 \mathrm{c}$ and $\mathrm{d}$ compare the evolutions of the mean CSD respectively with the number of cycles, or with the local crack depth, during all the mode I + III tests. Such a rise in CSD -which, at first sight, might look like a mere consequence of the increase in the elastic torsional compliance of the specimen when the crack grows deeper- had never been reported for tests run with a static torque, because the CSD was not monitored. It deserves some emphasis though, because it has consequences in terms of RICC, as discussed later, not to mention the erasure of the beach marks. For a given axial loading range, the higher the mean torque, the higher the mean CSD during the first loading cycle, but the lack of a linear correlation, -at a stage when the crack front, issued from compressive precracking, is still circular and nearly concentric- suggests a significant influence of monotonic plastic flow at the crack tip. It will be shown below that crack tip cyclic plasticity and, more specifically, a plastic ratchetting effect, actually contributes to the observed progressive relative rotation of the top and bottom halves of the samples.
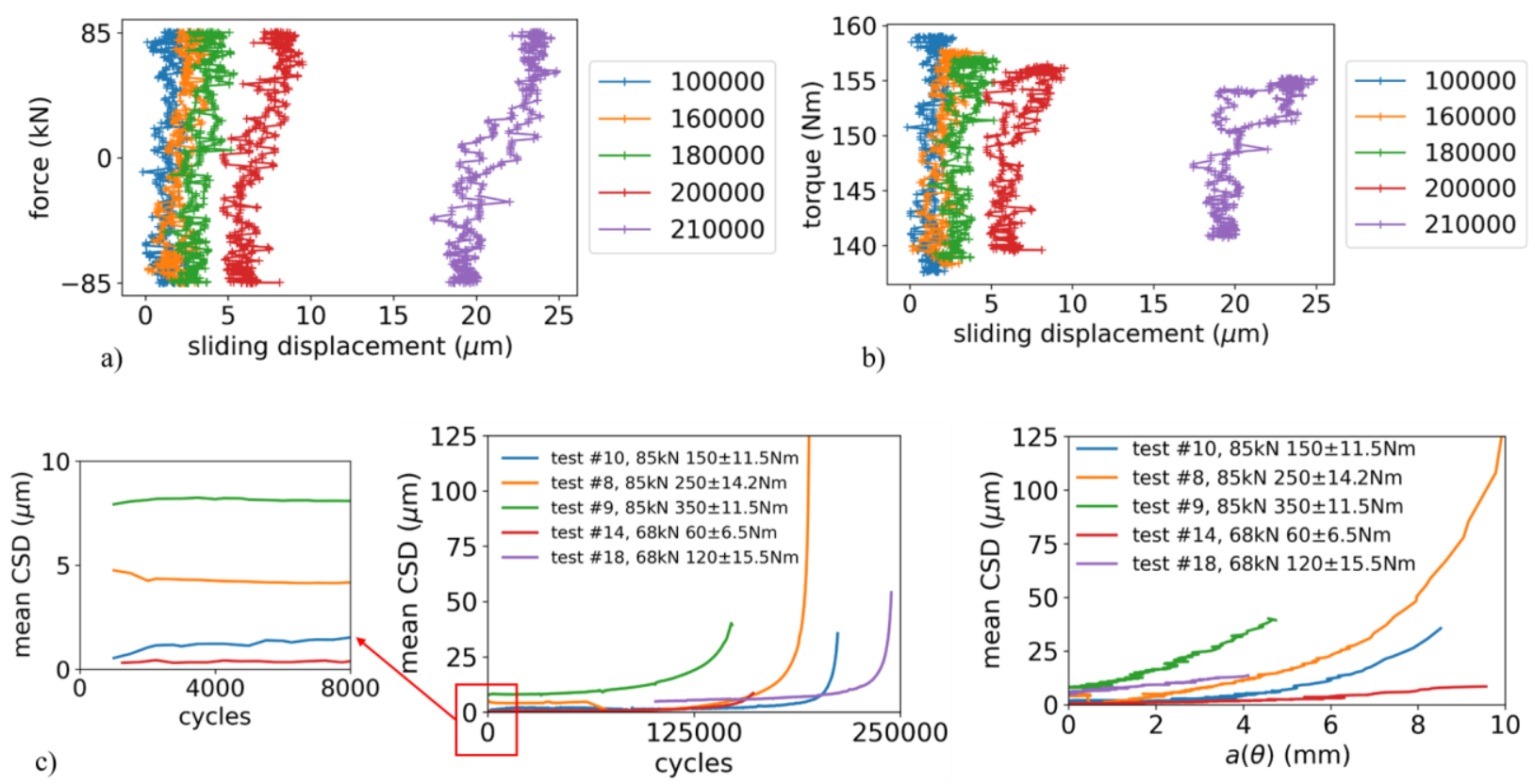

Figure 13: a) axial load - CSD and b) torque - CSD loops, at various stages of test \#10 $( \pm 85$ $\mathrm{kN}, \mathrm{M}=150 \pm 11.6 \mathrm{Nm}$ ), and c) compared evolutions of the mean CSD during all mode I + III tests, with the number of cycles or with the local crack depth 


\section{Elastic-plastic simulations}

Two types of elastic-plastic FE simulations were run, using constitutive equations with isotropic and non-linear kinematic hardening identified from strain-controlled push-pull tests, as described in the Appendix: 1) simulations with a stationary crack front to explain the ratchetting sliding displacement observed during the mixed-mode tests and 2) simulations with repeated node release, to assess the effect of a static torque on plasticity-induced crack closure (PICC). In the latter case, at each cycle, the first node ahead of the tip is released, and the axial loading range and torque are slightly reduced, so as to keep $\Delta \mathrm{K}_{\mathrm{I}}$ and the static $\mathrm{K}_{\mathrm{III}}$ constant. In both cases, the axisymmetric FE model, made of linear elements was that shown on Figure 14, with a fine and regular mesh around the crack tip. The mesh size there was adapted as a function of the simulated $\Delta \mathrm{K}_{\mathrm{I}}$, so that the cyclic plastic zone always contained at least 5 elements, as recommended for a correct estimation of PICC. Unilateral contact conditions were imposed, to prevent crack face interpenetration.
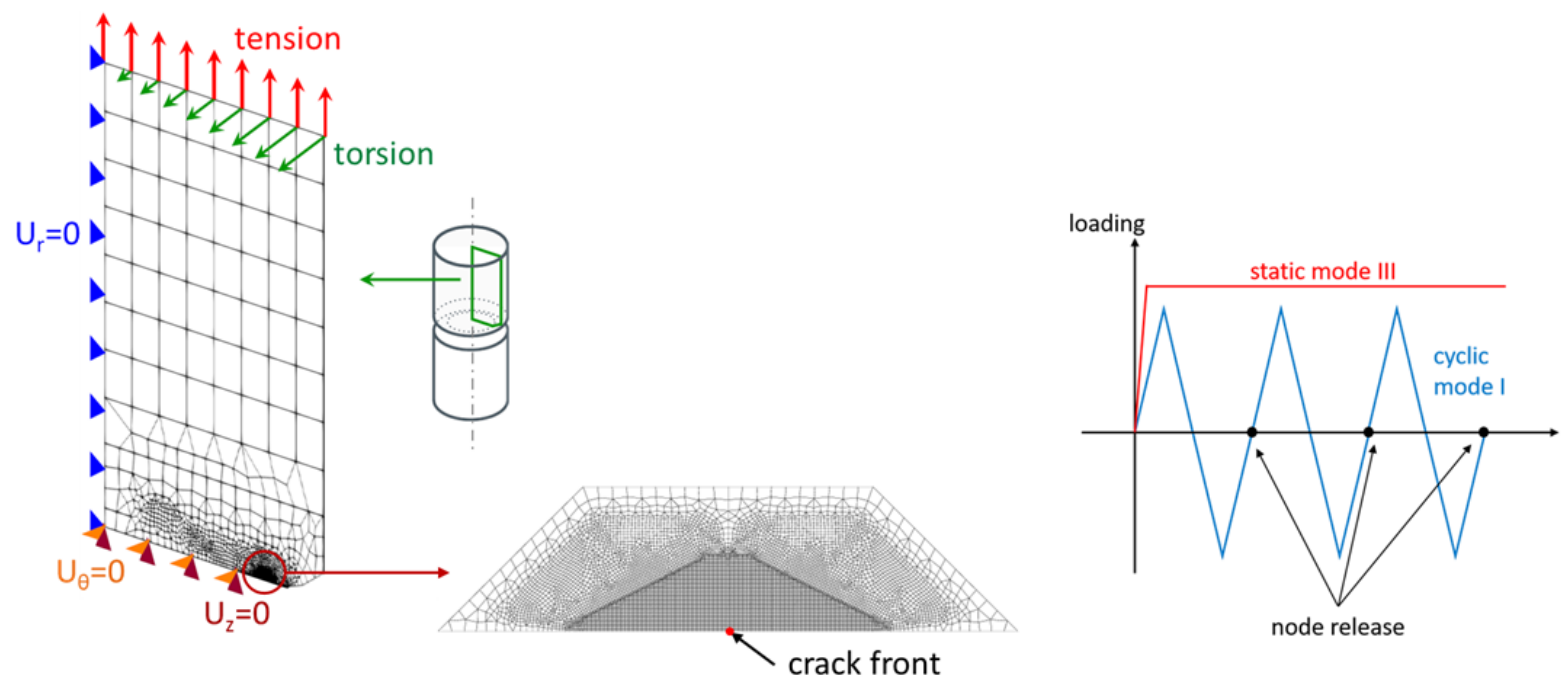

Figure 14: Axisymmetric finite element model used for the elastic-plastic simulations

Figure 15a-c correspond to an initially $1.6 \mathrm{~mm}$ deep crack under an axial load of $\pm 85 \mathrm{kN}$ (which corresponds to $\Delta \mathrm{K}_{\mathrm{I}}=17.5 \mathrm{MPa} \sqrt{ } \mathrm{m}$ ), and various torsional loadings. Fig. 15a shows the computed crack opening profiles at peak tensile load, for various static torques, before any node release. LEFM would predict parabolic profiles, independent of the torque, but elastic-plastic simulations reveal a large torque-induced increase in the initial crack tip blunting. Figure 15b compares the initial profiles of the axial plastic strain range $\left(\Delta \varepsilon^{\mathrm{p}}{ }_{\mathrm{zz}}\right)$ ahead of the crack front, and shows that before any crack propagation, the static torque increases the plastic strain range, as well as the monotonic plastic zone size, as shown by Figure $15 \mathrm{c}$. However, figures $15 \mathrm{~d}$ and $15 \mathrm{e}$, as well as the second curve in Fig. 15c obtained after 114 nodes released show that these are only transient effects, due to monotonic plastic flow, which either vanish after some crack growth and cyclic plasticity (effect on $\Delta \varepsilon_{\mathrm{p}}$ ) or are even reversed (opening displacement, monotonic plastic zone size). 


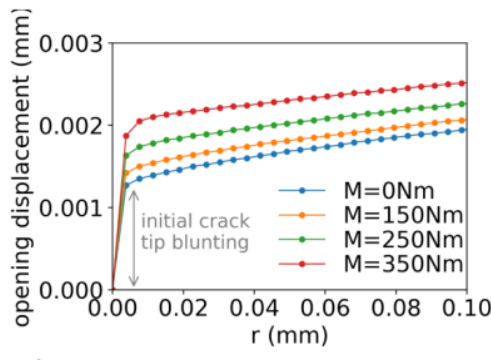

a)

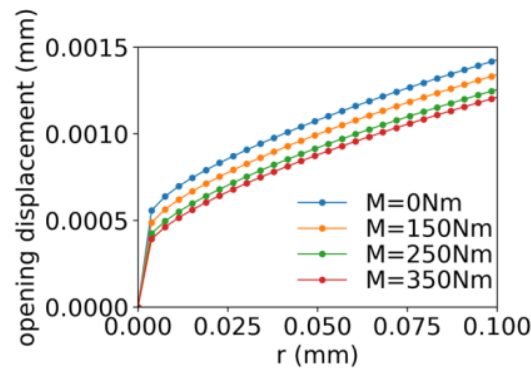

d)

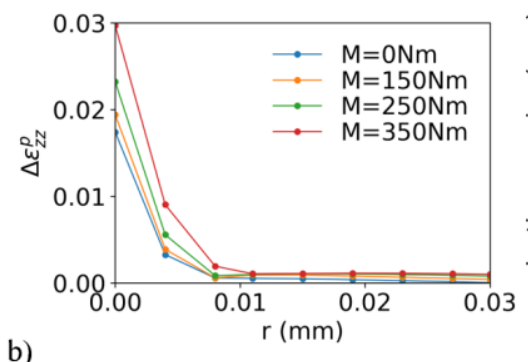

b)

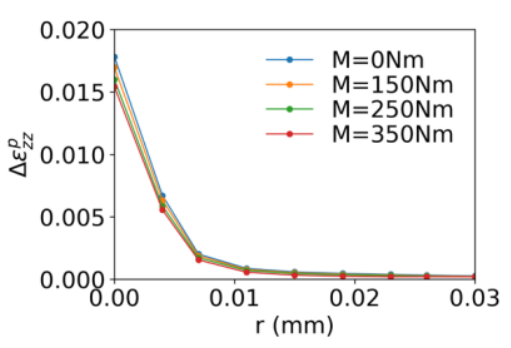

e)

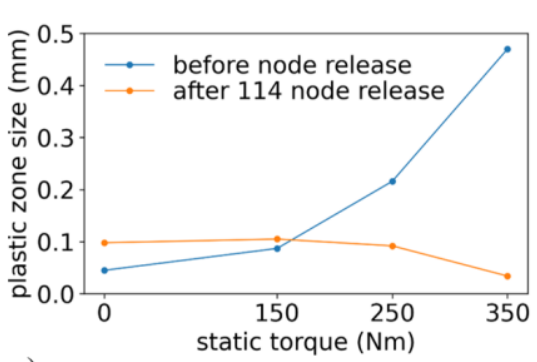

c)

Figure 15: Results of elastic-plastic FE simulations for an initially $1.6 \mathrm{~mm}$ deep crack, for $\Delta \mathrm{K}_{\mathrm{I}}=17.5 \mathrm{MPa} \sqrt{\mathrm{m}}$, and various static torques a) initial crack opening profiles at peak tensile load, before any node release b) initial profiles of the axial plastic strain range ahead of the crack front, c) final crack opening profiles at peak tensile load, after 114 nodes released d) final profiles of the axial plastic strain range ahead of the crack front, after 114 nodes released e) initial and final plastic zone sizes,

Figure 16a compares the evolutions, during 90 cycles at $\pm 85 \mathrm{kN}\left(\Delta \mathrm{K}_{\mathrm{I}}=17.5 \mathrm{MPa} \sqrt{\mathrm{m}}\right)$ and various torques, of the mean crack sliding displacement, $4 \mu \mathrm{m}$ behind the tip, for a $1.6 \mathrm{~mm}$ deep stationary crack . The initial CSD, which reflects monotonic plasticity, rises with the torque, but also with the peak axial load, as in the experiments (see Fig. 13a), and a ratchetting increase is predicted. The ratcheting rates are plotted on Fig. 16b. It rises with both $\mathrm{F}_{\max }$ and $\mathrm{M}$. For a stationary crack, ratchetting is predicted to slow down, while in the experiments an acceleration is observed, both in terms of number of cycles and crack depth. This is probably due 1) to the fact that the rise in CSD partly results from the increase in torsional elastic compliance, which accelerates with crack depth, and that the latter was fixed in the simulations, 2) that the CSD measurements were made on the outer surface of the specimens, at a rising distance from the crack front, while in the simulations, the CSD was computed at a fixed distance. A third reason is the rise in $\Delta \mathrm{K}_{\mathrm{I}}$ and $\mathrm{K}_{\mathrm{III}}$ associated with crack growth, and the resulting increase in crack tip plasticity, which was not modelled. Note that these simulations were run for a smooth and frictionless crack. They do not take into account crack face roughness, which, if the asperities were rigid, should prevent the rise of the CSD. The occurrence and importance of this rise in the experiments is thus a clear indication that the asperities progressively get sheared. The incremental, ratchetting character of this shearing, and the substantial ductility of the steel probably enhanced by the compression of the asperities- as well as the fact that most of the rise in CSD occurs within the last $20 \%$ of the fatigue life (see fig 13c) might explain the quasi absence of debris on the fracture surfaces. 

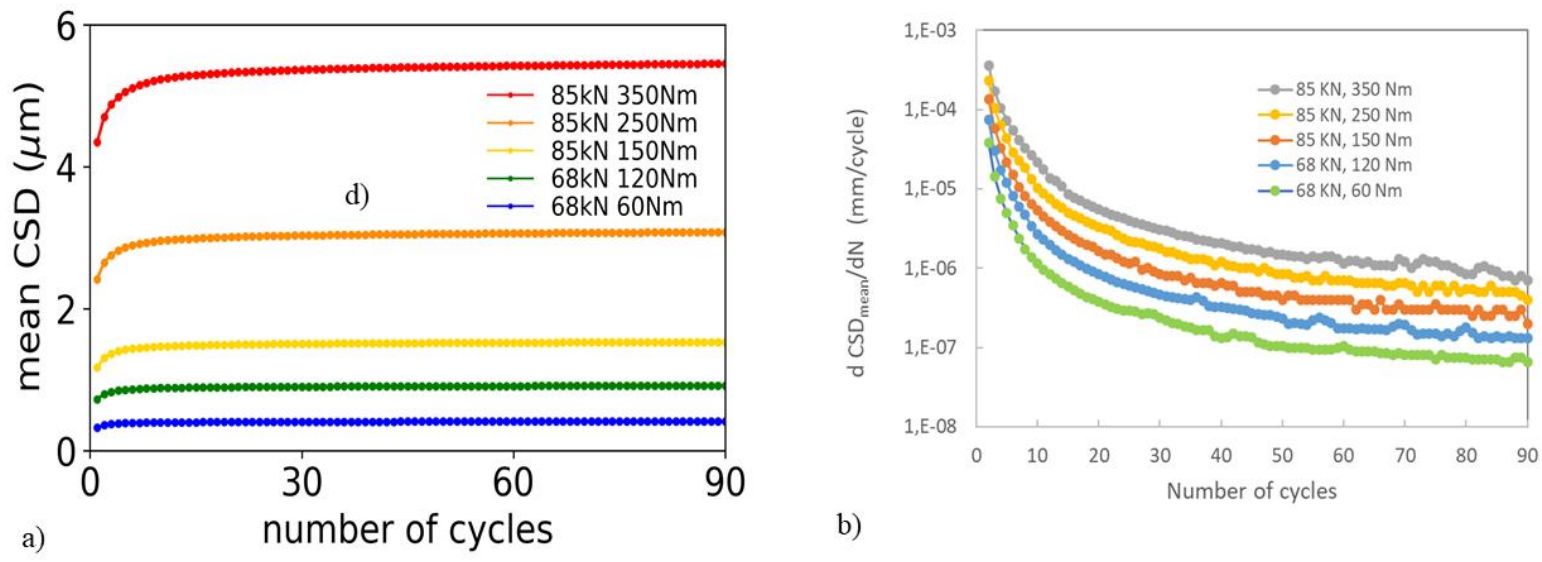

Figure 16. Evolution of the crack sliding displacement, $4 \mu \mathrm{m}$ behind the tip, during 90 cycles at $\pm 85 \mathrm{kN}\left(\Delta \mathrm{K}_{\mathrm{I}}=17.5 \mathrm{MPa} \sqrt{\mathrm{m}}\right)$ and various static torques for a stationary, $1.6 \mathrm{~mm}$ deep crack. a) evolutions of the mean CSD over each cycle, b) rate of evolution of the mean CSD.

Figure 17 corresponds to an initially $1.6 \mathrm{~mm}$ deep crack propagating under cyclic axial loading with $\mathrm{R}=-1$ or $\mathrm{R}=0$, and various axial and torsional loadings. $\mathrm{K}_{\text {closure }}$ corresponds to the load for which the COD at the first node behind the tip vanishes, upon unloading. Fig. 17a shows that for $\mathrm{R}=-1$, during the first cycle before any node release, a $200 \mu \mathrm{m}$-long portion behind the tip remains open during the whole compressive stage, due to the large initial crack tip blunting mentioned above. Fig. 17b shows that when 114 nodes have been released, closure occurs earlier for $\mathrm{F} / \mathrm{F}_{\max }=-0.61$.

Figure $17 \mathrm{c}$ and $\mathrm{d}$ compare the computed evolutions of $\mathrm{K}_{\text {closure }} / \mathrm{K}_{\max }$ for $\Delta \mathrm{K}_{\mathrm{I}}=9.3 \mathrm{MPa} \sqrt{\mathrm{m}}$ and various values of the torque, for $\mathrm{R}=0$ and -1 , respectively, until a steady-state is reached. This steady-state value was used to compute $U=\Delta K_{I}^{\text {eff }} / \Delta K_{I}^{\text {nom }}$. For a given $K_{\text {Imax }}$, $U$ was always larger for $\mathrm{R}=-1$ than for $\mathrm{R}=0$, which means that the compressive stage of the cycle increases the crack driving force. To highlight the effect of a steady mode III on PICC, U was normalized by its value in pure mode I for the same $\Delta \mathrm{K}_{\mathrm{I}}$, denoted by $\mathrm{U}_{0}$, and plotted versus the mode mixity ratio on Fig. 17e for $R=0$ and -1 , for two values of $\Delta K_{I}$. In all cases, the presence of a steady mode III enhances plasticity-induced closure, and the effect is more pronounced for $\mathrm{R}=0$, and at low $\Delta \mathrm{K}_{\mathrm{I}}$. Note that the decrease in $\mathrm{U}$ seems to slow down or even saturate at high torque. Surprisingly, this mode III-induced enhancement of PICC is the opposite of what was found for a static mode II [24]. The reason for this difference is not clear. It is not an effect of the constitutive equations used in the present study, since the same crack growth simulations under cyclic mode I plus static mode II as in [21] run with these equations retrieved the reduction of PICC found in the previous study. 


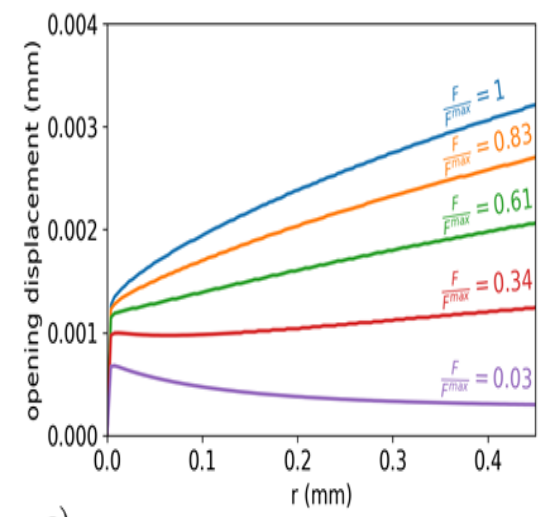

a)

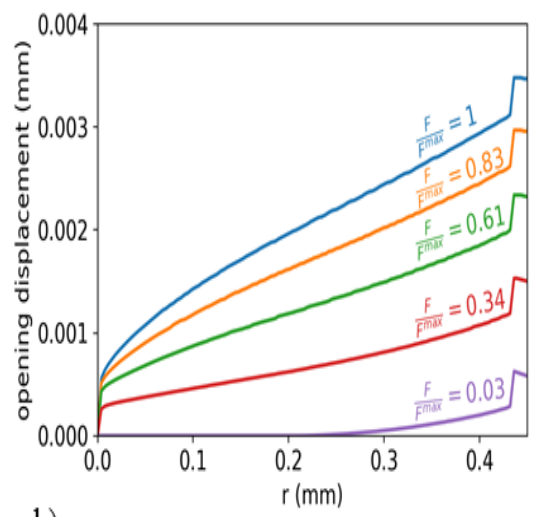

b)

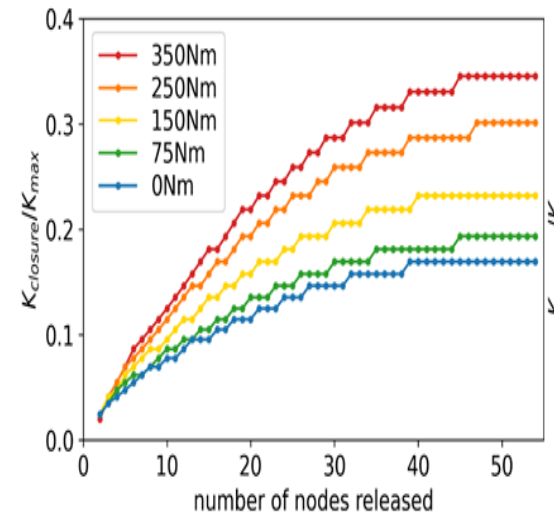

c)

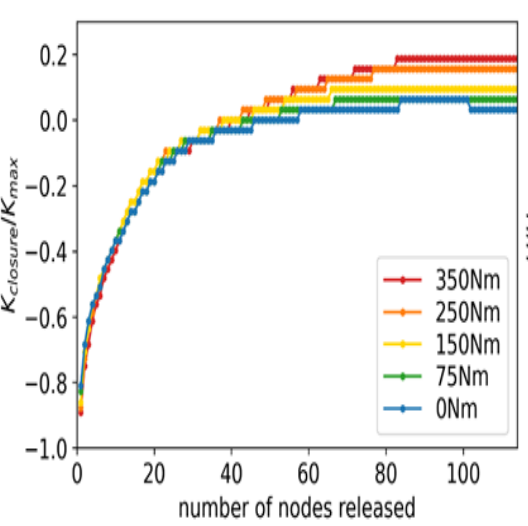

d)

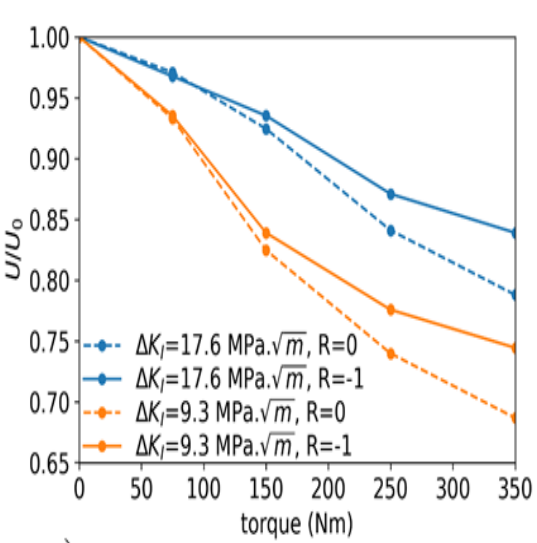

e)

Figure 17: Elastic-plastic FE simulation of PICC. a-b) crack opening displacement profiles upon unloading for $\Delta \mathrm{K}_{\mathrm{I}}=17.6 \mathrm{MPa} \sqrt{\mathrm{m}}$, a) before any node release, and b) after 114 nodes have been released, c-d ) evolutions of $\mathrm{K}_{\text {closure }} / \mathrm{K}_{\max }$, for $\Delta \mathrm{K}_{\mathrm{I}}=9.3 \mathrm{MPa} \sqrt{\mathrm{m}}$ and various static torques, for $\mathrm{R}=$ 0 (c), or $\mathrm{R}=-1$ (d), and e) influence of a static torque on the steady-state $\mathrm{U}$, normalized by its value in mode I

\section{IV.3. Incremental simulations of fatigue crack growth}

Incremental FE simulations of the eccentric growth of a more or less elliptical crack, based on the mode I crack growth kinetics, were run and their predictions were compared with the experimental observations. An initial eccentricity defect of $0.2 \mathrm{~mm}$ was assumed in all cases. At each iteration, after computing the SIFs at all nodes along the crack front, a local crack growth rate was deduced, and the increment in the number of cycles was adjusted, so that the increment in crack depth did not exceed a specified value, at any point along the front. The mesh was then updated and the loop started again. A fully elastic behavior was assumed. The simulations were stopped well before the condition for unstable fracture are met, because it is based on linear elastic fracture mechanics (LEFM), and during the last stages of fatigue crack growth, smallscale yielding conditions did not prevail anymore.

The FE model also allows the computation of the compliance that would be measured by an extensometer or by a camera monitoring a marker pair, as well as of the DC potential drop at any angular position along the front. For the former, the relative axial displacement of two nodes located above and below the crack plane on the outer surface, at a distance corresponding to the gage length was divided by the applied load. For the latter, a thermal analogy was used, as 
previously done by Ritter et al [29] for the calibration of their DC-PD system, for a centered circular crack: a thermal flux parallel to the specimen axis was imposed at one specimen end, the temperature difference across the ligament was set to zero, and the temperature difference between two nodes located $1 \mathrm{~mm}$ above and below the crack plane, at any angular position on the outer surface was computed. Fractographic observations allow the determination of the angular positions of the extensometer, cameras and electric probes for each test. The simulated evolutions of their signals during eccentric crack growth can then be compared to the measured evolutions, and the degree of agreement can be used to validate the crack growth model.

The crack growth rate was computed as:

$$
\frac{d a}{d N}=C\left\langle U . \Delta K_{I}-\Delta K_{\text {threshold }}\right\rangle^{m}
$$

with $\Delta \mathrm{K}_{\text {threshold }}=6 \mathrm{MPa} \sqrt{\mathrm{m}}$. This value was estimated based on the crack growth rate during the marker blocks.

The simulations were first run assuming a constant and uniform value of $U$, denoted as $U_{\text {mean }}$, which was adjusted for each test. The coefficients $\mathrm{C}$ and $\mathrm{m}$ were first identified, by trial and error, $\left(\mathrm{m}=3.5, \mathrm{C}=2.5 \times 10^{-12}\right.$ with $\mathrm{da} / \mathrm{dN}$ in $\mathrm{m} /$ cycle $)$ so as to reproduce approximately the successive positions and shapes of the crack front evidenced by the marker blocks, as well as the evolutions of the compliance and DC potential drop measured at various angular positions, during the two tests run in mode I. Even though such an approach neglects the gradient of U along the front and its evolutions during the test (limited after the first $2 \mathrm{~mm}$ of crack growth), it allows a rather satisfactory capture of the crack front evolutions and of the measured compliance and potential drop, during test \#7 (assuming $\mathrm{U}_{\text {mean }}=1.1$ ) and test \#13 (assuming $\mathrm{U}_{\text {mean }}=1.23$ ), as illustrated by Fig 18, and Table 3, which compares, at $\theta=180^{\circ}$, the number of cycles at the beginning of each of the four marker blocks applied during test \#7 and the three marker block during test \#13 with the numbers predicted by the simulations.
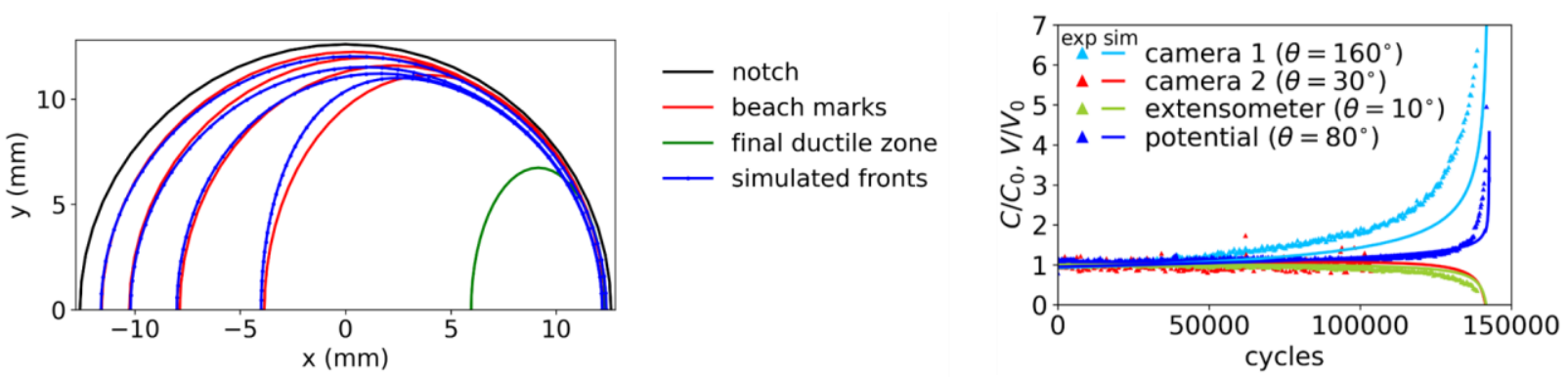

a) test \#7, $85 \mathrm{kN}$

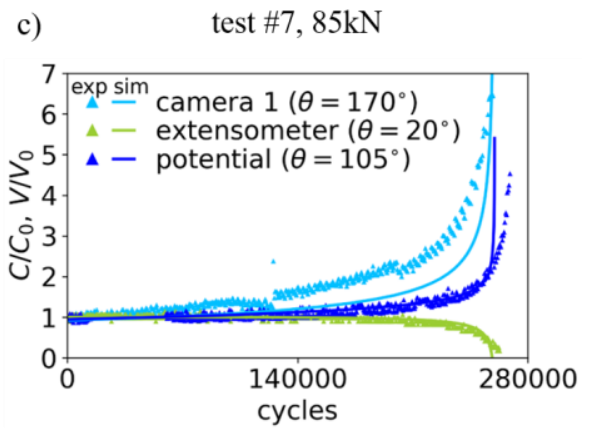

d)

test \#13, $68 \mathrm{kN}$

Figure 18: Incremental FE simulations of crack growth for tests \#7 and \#13 run in mode I, using a constant and uniform value of $\mathrm{U} a-b)$ observed and simulated consecutive positions and shapes of the front, and c-d) comparison of measured and computed evolutions of the local compliance and potential drop. 


\begin{tabular}{|c|c|c|c|}
\hline Marker block & $\begin{array}{c}\text { Number of cycles at } \\
\text { the beginning of the } \\
\text { block at } \theta=180^{\circ}\end{array}$ & $\begin{array}{c}\text { Number of cycles } \\
\text { retrieved by the } \\
\text { simulation }\end{array}$ & \% error \\
\hline Test \#7, mark 1 & 60000 & 67954 & $13 \%$ \\
\hline Test \#7, mark, 2 & 100000 & 120212 & $20 \%$ \\
\hline Test \#7, mark 3 & 125000 & 137170 & $9.7 \%$ \\
\hline Test \#7, mark 4 & 137500 & 141981 & $3.2 \%$ \\
\hline Test \#13, mark 1 & 120000 & 128901 & $13.5 \%$ \\
\hline Test \#13, mark 2 & 200000 & 227064 & $2.6 \%$ \\
\hline Test \#13, mark 3 & 250000 & 256645 & $20 \%$ \\
\hline Test \#14, mark 1 & 120000 & 144736 & $11.9 \%$ \\
\hline Test \#18, mark 1 & 200000 & 223842 & \\
\hline
\end{tabular}

Table 3: Number of cycles at the beginning of each of the marker blocks and number of cycles predicted by the incremental simulations

Then, keeping $\mathrm{C}, \mathrm{m}$, and $\Delta \mathrm{K}_{\text {threshold }}$ unchanged, the tests run in mode I + III were simulated, and for each test, the parameter $U$ was optimized, so as to capture the evolutions of the compliance and potential drop measured at various angular positions. The measured and simulated evolutions are compared on Figure 19, and the adjusted values of $U_{\text {mean }}$ are indicated in Table 4, where the value of $U$ measured in the angular sector where crack growth was fastest are also indicated for comparison. In six cases out of seven, the former, which reflects an average over the whole crack front is smaller than the latter, which rather represent the most favorable conditions for crack growth. 


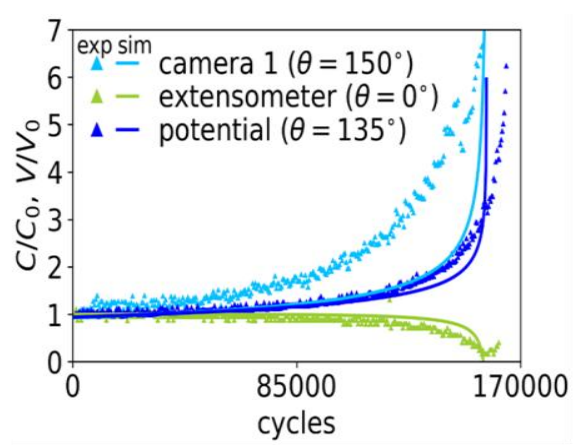

a)

test \#14, $68 \mathrm{kN}-60 \mathrm{Nm}$

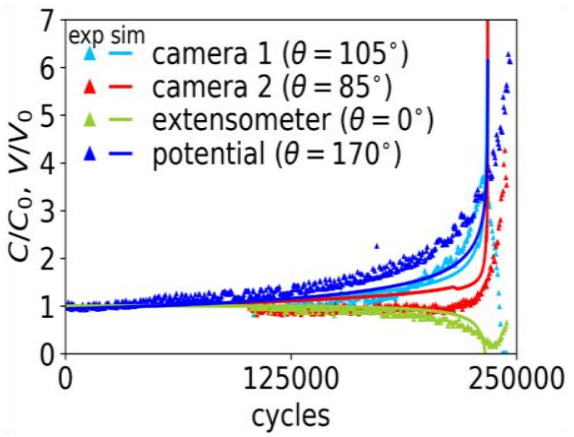

b)

test \#18, 68kN - 120Nm

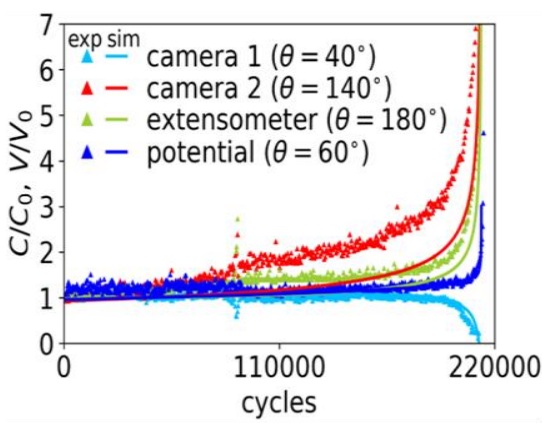

c) test $\# 10,85 \mathrm{kN}-150 \mathrm{Nm}$

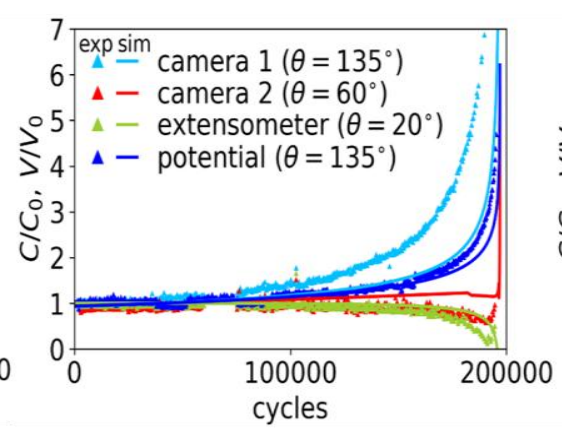

d) test $\# 8,85 \mathrm{kN}-250 \mathrm{Nm}$

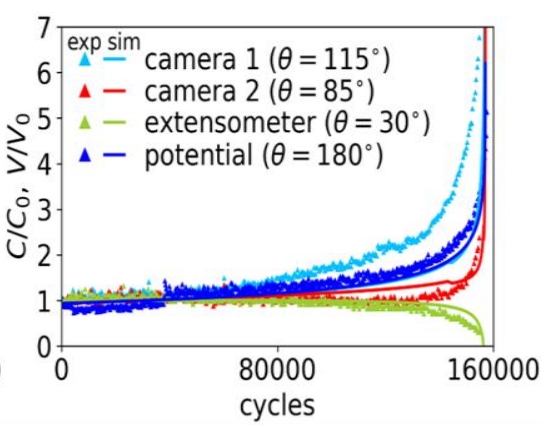

e) test \#9, $85 \mathrm{kN}-350 \mathrm{Nm}$

Figure 19: Incremental FE simulations of crack growth for the tests run in mixed-mode, using a constant and uniform value of U. a-e) comparison of measured and computed evolutions of the local compliance and potential drop

\begin{tabular}{|c|c|c|c|c|}
\hline Test & Axial load & Torque & $\begin{array}{c}\text { Measured } \\
\mathrm{U}\left(\theta=180 \pm 30^{\circ}\right)\end{array}$ & $\begin{array}{c}\text { Adjusted } \\
\mathrm{U}_{\text {mean }}\end{array}$ \\
\hline$\# 7$ & $\pm 85 \mathrm{kN}$ & 0 & 1,27 & 1.1 \\
\hline$\# 10$ & $\pm 85 \mathrm{kN}$ & $150 \pm 12.6 \mathrm{Nm}$ & 1,16 & 1.02 \\
\hline$\# 8$ & $\pm 85 \mathrm{kN}$ & $250 \pm 14.2 \mathrm{Nm}$ & 1,18 & 1.035 \\
\hline$\# 9$ & $\pm 85 \mathrm{kN}$ & $350 \pm 11.2 \mathrm{Nm}$ & 1,23 & 1.23 \\
\hline$\# 13$ & $\pm 68 \mathrm{kN}$ & 0 & 1,25 & 1.35 \\
\hline$\# 14$ & $\pm 68 \mathrm{kN}$ & $60 \pm 6.1 \mathrm{Nm}$ & 1,35 & 1.255 \\
\hline$\# 18$ & $\pm 68 \mathrm{kN}$ & $120 \pm 15.5 \mathrm{Nm}$ & 1,17 & \\
\hline
\end{tabular}

Table 4. Measured and adjusted values of $U$

Figure 20 compares the simulated crack fronts (plotted in orange) to the only two beach marks still visible after tests run in mixed mode (test \#14 and test \#18). Using a uniform value of U along the whole front, crack growth is overestimated in the areas where $\mathrm{K}_{\mathrm{III}}$ is highest. 


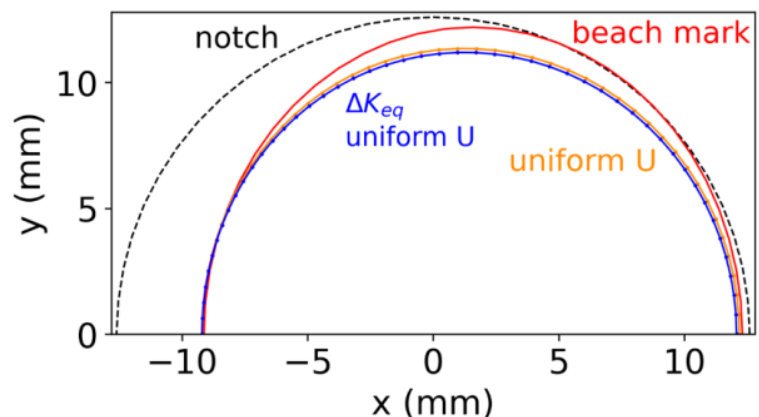

a)

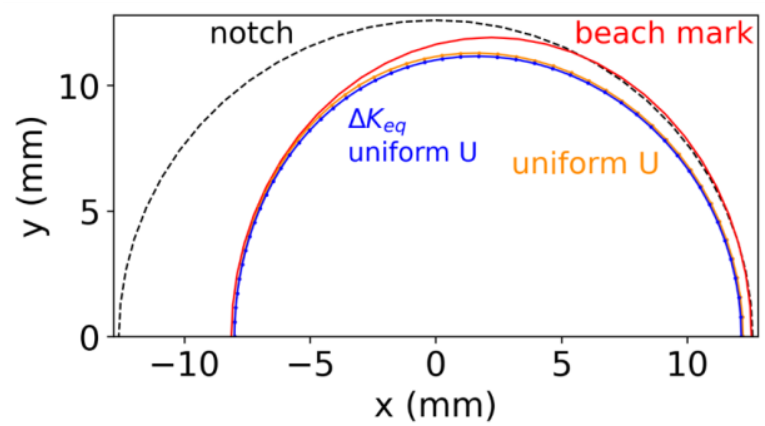

c)

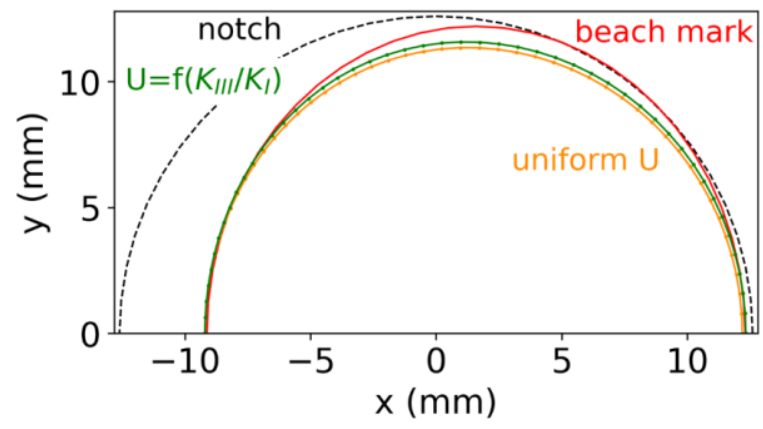

b)

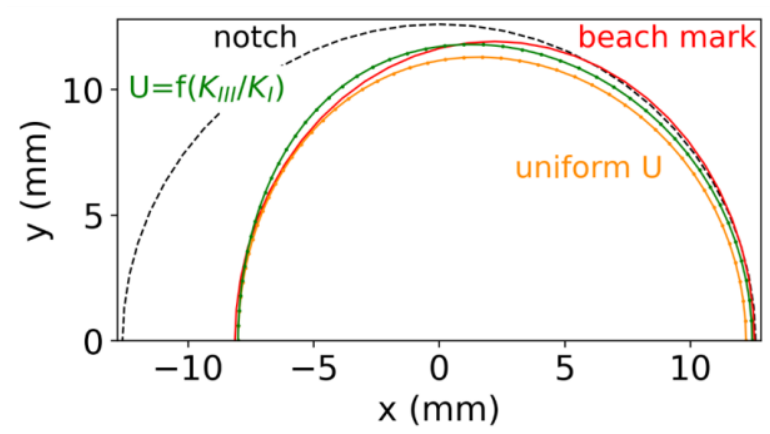

d)

Figure 20: Comparison of simulated crack front shapes with the observed beach marks for a-b) test \#14 ( $\pm 68 \mathrm{kN}, 60 \mathrm{Nm})$ and c-d $)$ test \#18 ( $\pm 68 \mathrm{kN}, 120 \mathrm{Nm})$

When the contribution of $\Delta \mathrm{K}_{\mathrm{III}}$ associated with the small fluctuations of the torque is taken into account, by inserting into the mode I Paris equation an "equivalent" $\Delta \mathrm{K}$ inspired from the expression of the energy release rate [35]:

$$
\Delta K_{e q}=\sqrt{\Delta K_{I}^{2}+\frac{\Delta K_{I I I}^{2}}{1-v}}
$$

the effect on the predicted crack fronts (plotted in blue) is negligible, as visible on Figure 20a and 20c, for tests \#14 and \#18, respectively.

To reduce the discrepancy, an attempt was made to incorporate an effect of the static torque on crack closure effects. To simulate the growth of a transverse crack in a rotating shaft in presence of a steady torque, Nikravesh et al. [11] introduced a dependence of $\mathrm{K}_{\text {closure }}$ on $\mathrm{K}_{\text {III }}$ based on the assumption that the torque induces local crack twisting in accordance with the MTS criterion (which is not the case here, as shown above). They used a micromechanical model of roughness-induced closure. This model however predicts no RICC at all if no torque is present, which would not seem realistic in the present case, considering the roughness and presence of twisted facets in that case as well. Here, a purely empirical dependence of $U$ on the local mode mixity ratio was introduced, as:

$$
U=U_{0}\left(1-a\left(1-e^{-b \frac{K_{I I I}}{K_{I}}}\right)\right.
$$

In mode $I, U$ is equal to $U_{0}$, and is supposed to decrease and saturate at $U_{0}(1-a)$ when the mode mixity ratio rises. The crack fronts predicted with $a=0.4$ and $b=6$ are plotted in green on Figure $20 \mathrm{~b}$ and $20 \mathrm{~d}$, for tests \#14 and \#18, respectively. The agreement with experiment is 
significantly improved for test \#18 but not sufficiently for test \#14. It proved difficult to find values of $\mathrm{a}$ and $\mathrm{b}$ suitable for both test conditions.

\section{Discussion}

For the bainitic steel and the loading conditions investigated here, the effect of the superimposed torque on the fatigue lives of the specimens was quite limited compared to the large beneficial effect reported in the literature. Furthermore, the effect did not seem to rise monotonically with the torque.

The incremental simulations described above have shown that the contribution of the small $\Delta \mathrm{K}_{\mathrm{III}}$ induced by the fluctuations of the torque to the crack driving force is unlikely to explain why the enhancement of the fatigue life is so modest, or even not observed. These small fluctuations may however have contributed to crack face wear. But shearing of crack face asperities and the erasure of most crack front markings are more probably due to the progressive increase in the crack sliding displacement. This reduces asperity-induced closure effects, and thus limits the beneficial effect of a steady torque. Since this ratchetting effect rises with the torque, and since the enhancement of plasticity-induced closure also seems to saturate at high torque (as illustrated by Fig. 17e), the beneficial effect of the torque thus tends to saturate, as also noticed by $\mathrm{Lu}$ et al. [17]. The local twist angle increased slightly with crack depth, but were much smaller than predicted by the MTS criterion. Xu et al. [36] and Leblond et al. [37] have proved by theoretical analyses the existence of a threshold $\mathrm{K}_{\mathrm{III}} / \mathrm{K}_{\mathrm{I}}$ below which crack front perturbations consisting of periodic twisted facets tend to vanish as the crack propagates under monotonic loading, which means that coplanar growth is stable at low mode mixity ratio. The threshold was shown to be a function of the Poisson's ratio, and to lie around 0.52 for $v=0.3$. To determine if such a threshold $\mathrm{K}_{\mathrm{III}} / \mathrm{K}_{\mathrm{I}}$ for local crack twisting also exists in fatigue, the local twist angles measured by profilometry were plotted versus the local mode-mixity ratio on Figure 21 . This plot does not support the existence of a threshold for crack twisting in fatigue.

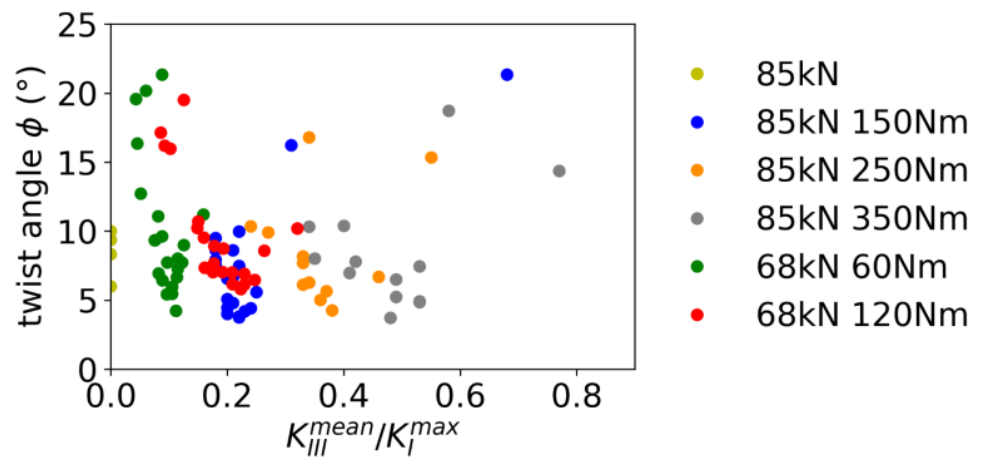

Figure 21: Local twist angles versus the local $\mathrm{K}_{\text {III }} / \mathrm{K}_{\text {Imax }}$

In fatigue with a static torque, Hourlier \& Pineau [13] measured different twist angles in different materials for the same mode mixity ratio. Furthermore, these angles were always much smaller than predicted by the MTS criterion or even equal to zero. They explained it using the maximum growth rate criterion (MGR). Crack twisting towards a facet which undergoes a torque-induced static tension raises $\mathrm{K}_{\mathrm{Imax}}$, and the $\mathrm{R}$ ratio, but reduces $\Delta \mathrm{K}_{\mathrm{I}}$. Depending on the degree of influence of the $\mathrm{R}$ ratio on the mode I kinetics, the growth rate on such a twisted facet can either be higher than along the normal plane, this triggering crack twisting, or not, and in that case, twisting should not occur. In order to try such an approach, mode I fatigue crack 
growth tests were run at $\mathrm{R}=0.5,0,-0.5$ and -1 on the investigated steel, using $7 \mathrm{~mm}$-thick, 30 mm-wide SENT specimens with threaded heads. Figure 22 compares the measured kinetics. At low $\Delta \mathrm{K}_{\mathrm{I}}$, crack growth is faster at $\mathrm{R}=-1$, and $\Delta \mathrm{K}_{\text {threshold }}$ is smaller than at $\mathrm{R}=-0.5$ or $\mathrm{R}=0$, while the influence of the $R$ ratio vanishes in the Paris regime. So, according to the MGR criterion, a superimposed static torque should not induce crack twisting in this steel.

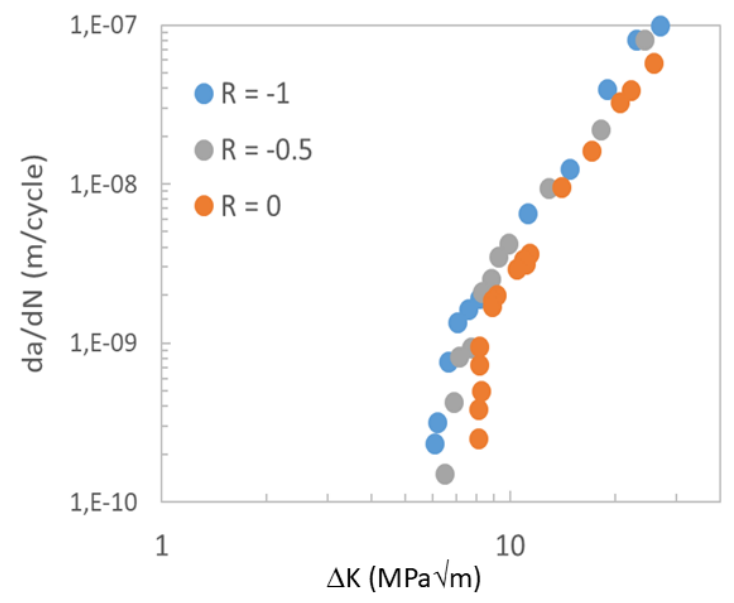

Figure 22: Mode I crack growth kinetics measured at various $\mathrm{R}$ ratios using SENT specimens

An alternative explanation to the rise of the measured twist angles with crack depth emerges from the observation that crack twisting also occurs in pure mode I (see Fig. 10). This suggests an effect of the non-singular stress parallel to the front, which becomes more and more positive as the crack grows inwards. In $3 \mathrm{D}$, the asymptotic stress field close to the crack front can be described by singular terms, associated with $\mathrm{K}_{\mathrm{I}}, \mathrm{K}_{\mathrm{II}}, \mathrm{K}_{\mathrm{III}}$, and non-singular tensile or compressive terms, $\mathrm{T}$ and $\mathrm{S}$, respectively normal and parallel to the front, and potentially a nonsingular shear stress as well, but the latter is zero for a concentric circumferential crack in a cylinder loaded in tension and torsion, for which the only non-zero terms are:

$$
\begin{aligned}
& \sigma_{r r}=\frac{K_{I}}{\sqrt{2 \pi r}} f_{r r}(\theta)+T \\
& \sigma_{\theta \theta}=\frac{K_{I}}{\sqrt{2 \pi r}} f_{\theta \theta}(\theta)+S \\
& \sigma_{z z}=\frac{K_{I}}{\sqrt{2 \pi r}} f_{z z}(\theta) \\
& \sigma_{\theta z}=\frac{K_{I I I}}{\sqrt{2 \pi r}} f_{\theta z}(\theta)
\end{aligned}
$$

Figure 23a (replotted from [38]) shows the evolutions with the normalized crack depth, a/W (where $\mathrm{W}$ denotes the radius of the cylinder), of the biaxiality ratios, $\beta_{T}=\frac{T \sqrt{\pi a}}{K_{I}} \quad$ and $\beta_{S}=$ $\frac{s \sqrt{\pi a}}{K_{I}}$ associated with the two non-singular stresses $\mathrm{T}$ and $\mathrm{S}$, obtained by elastic finite element computations. While the former remains constant and close to -0.5 whatever the crack depth, the latter is initially negative for shallow cracks, but rises as the crack grows, becomes positive for $\mathrm{a} / \mathrm{W}=0.3$ and more and more positive beyond that relative crack depth. Cotterel and Rice [39] 
have shown that a tensile $\mathrm{T}$ stress favors crack deviation (tilting) out of its initial plane, while a negative $\mathrm{T}$ stress makes coplanar growth more stable. Xu et al. [36] have shown that the S stress plays a similar role for crack twisting, which is favored by a positive $\mathrm{S}$ stress. In the present specimens, where $\mathrm{W}=15 \mathrm{~mm}$, if the cracks remained circular and centered, the $\mathrm{S}$ stress would thus be expected to remain negative and to hinder crack twisting as long as the total crack depth (including that of the $2.4 \mathrm{~mm}$ deep notch) is smaller than $4.5 \mathrm{~mm}$, that is until $2.1 \mathrm{~mm}$ crack growth from the notch root. Only beyond that depth would the rising tensile S stress be expected to favor crack twisting more and more. However, as illustrated by Fig. 9d, crack twisting occured much earlier in sample \#13, loaded only in tension, in the angular sector around $\pm 45^{\circ}$. To explain such an early instability of coplanar growth, an elastic F.E. computation of the normal and tangential stress profiles ahead of the front, at various angular positions along an eccentric elliptical crack (characterized by $a_{1}=6.3 \mathrm{~mm}, b_{1}=9 \mathrm{~mm}$, and $\mathrm{e}=5.5 \mathrm{~mm}$ ) in a specimen submitted to a tensile load of $68 \mathrm{kN}$ was performed, and the results are plotted on Fig. 23b. Due to bending-induced compression, at $\theta=0^{\circ}$, the crack remains closed at peak tensile load, and both the normal and tangential stresses are negative. At $\theta=47.6^{\circ}$, the normal stress is still negative (although the compression is less pronounced), while the tangential stress is positive, and is actually the first principal stress (the stress parallel to the crack growth direction being smaller). It is clear that such a stress state favors crack twisting. For $\theta=90^{\circ}$ and $180^{\circ}$, the crack is open, and $\mathrm{K}_{\mathrm{I}}$ is finite, so that both the normal and tangential stress are positive. Just ahead of the crack front, the tangential stress represents 55 to $65 \%$ of the opening stress, which is less favorable to crack twisting than around $\pm 45^{\circ}$.

Contrary to a torque-induced crack twisting, which would favor facets undergoing tension, a Sstress induced twisting can occur towards one side or the other. Since no asymmetry in the height profiles was observed, except at the very late stage of fatigue crack growth, and since the measured twist angle did not correlate with the local mode-mixity ratio, it seems that crack twisting in the present tests was rather triggered by the non-singular tangential stress than by the torsional loading.

Finally, the reasons why the fatigue lives of the specimens submitted to a steady torque were not much larger than those tested in pure mode I might partly be that in the latter, S stress-induced crack twisting reduced the crack growth rate, and thus enhanced the fatigue life, and partly a torque-induced shearing of crack face asperities which reduces RICC.

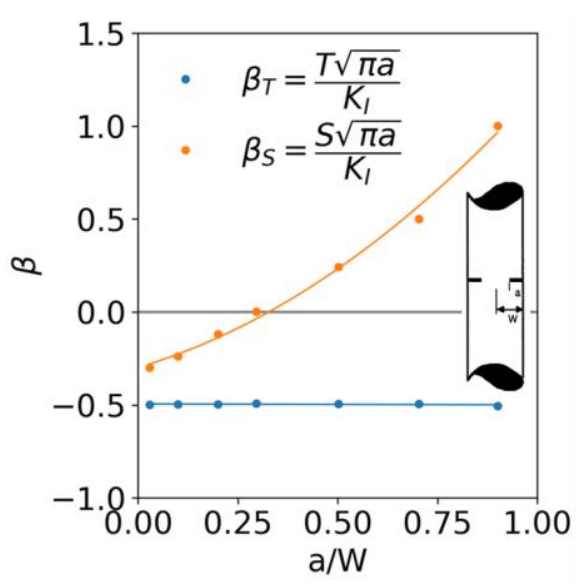

a)
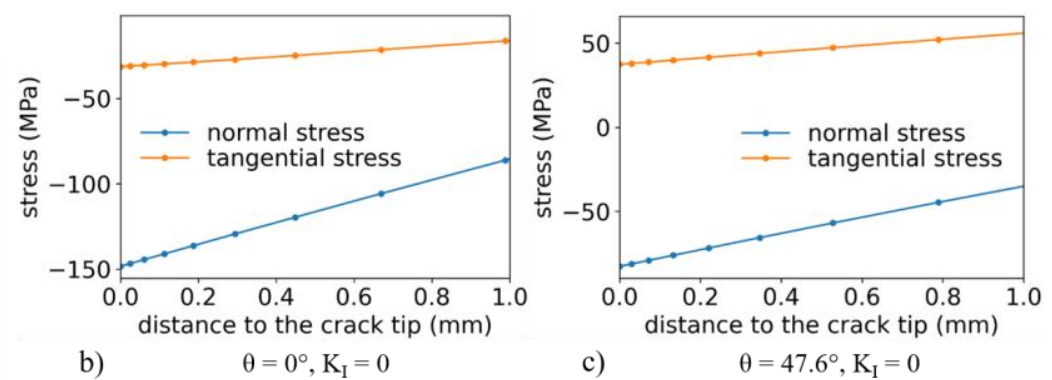

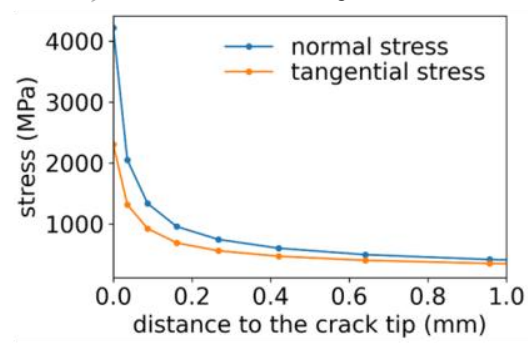

d) $\quad \theta=90^{\circ}, \mathrm{K}_{\mathrm{I}}=29.5 \mathrm{MPa} \sqrt{\mathrm{m}}$

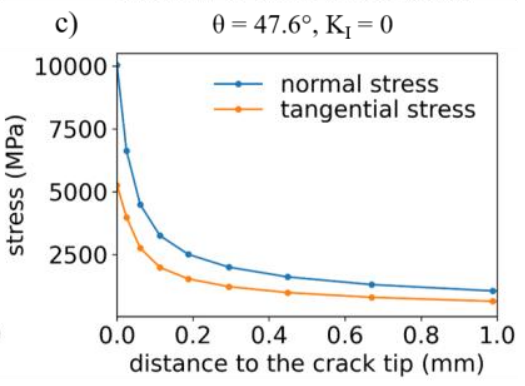

e) $\theta=180^{\circ}, \mathrm{K}_{\mathrm{I}}=88.2 \mathrm{MPa} \sqrt{\mathrm{m}}$

Figure 23: a) Evolutions with the normalized crack depth, a/W, of the biaxiality ratios, $\mathrm{b}_{\mathrm{s}}$ and $b_{t}$ associated with the two non-singular stresses $T$ and $S$ (normal and tangent to the front) for a circumferential circular crack in a cylinder loaded in tension (replotted from [38]) and b-e) normal and tangential stress profiles ahead of the front at various angular positions along an 
eccentric elliptical crack $\left(a_{1}=6.3 \mathrm{~mm}, b_{1}=9 \mathrm{~mm}, \mathrm{e}=5.5 \mathrm{~mm}\right)$ in a cylinder under a tensile load of $68 \mathrm{kN}$.

\section{Conclusions}

Eccentric, non-circular fatigue crack growth -a problem frequently encountered during tests on cylindrical specimens- does not necessarily imply that the data have to be discarded, provided that compliance or DC potential drop have been recorded at different angular positions along the surface. A numerical analysis taking crack eccentricity and shape into account to compute the stress intensity factors, and capturing the differences in measured evolutions at various angular positions is then possible. The data can thus still provide useful information about the crack growth kinetics and mechanisms.

In the bainitic steel investigated here, a nearly static superimposed torque had little effect on mode I crack growth kinetics, at $\mathrm{R}=-1$. The crack path was not significantly altered compared to pure mode I either, and in particular local crack twisting was not increased.

In circumferentially notched cylindrical specimens, a rising non-singular tensile stress is present parallel to the crack front and triggers crack twisting, even in pure mode I, especially when crack growth is eccentric and induces bending stresses which reduce, or even cancel $\Delta K_{I}$ along part of the crack front.

Elastic-plastic finite element simulations show that a steady torque superimposed on cyclic mode I loading enhances plasticity-induced closure, at $R=0$ or -1 , especially at low $\Delta K_{\mathrm{I}}$.

It was also shown that a steady torque triggers a progressive increase in crack sliding displacement, due to the rise of the torsional elastic compliance, but also to crack tip plasticity and more specifically to a plastic ratchetting effect, and to a progressive shearing of crack face asperities. This reduces the enhancement of roughness-induced closure by the torque and leads to a saturation of the beneficial effect at high $\mathrm{K}_{\text {III }}$, or high torque.

\section{Acknowledgments}

This work was supported by Naval Group and the French Defence Procurement Agency. In particular, the authors are grateful to Ludovic Jian, Christian Menard, Florent Bridier and Thierry Millot for useful discussions, and their constant interest in the study.

\section{Appendix: Identification of a constitutive equation}

The stress-strain loops recorded during strain-controlled push-pull tests at various strain ranges $( \pm 0.3 \%, \pm 0.5 \%, \pm 0.75 \%, \pm 1.0 \%$ and $\pm 1.5 \%)$ were fed to a Levenberg-Marquardt algorithm in order to fit constitutive equations using isotropic and non-linear kinematic hardening variables, according to Lemaitre and Chaboche's model [40] :

$$
f=\sqrt{3 J_{2}(\sigma-X)}-R=0
$$




$$
\begin{array}{r}
R=R_{0}+Q\left(1-e^{-b p}\right) \\
d X=C d \epsilon_{p}-D X d p \\
p=\int_{0}^{t}\left|\dot{\epsilon_{p}}\right| d t
\end{array}
$$

where $\mathrm{f}$ is the yield function, $\mathrm{X}$ is a non-linear kinematic hardening variable, $\mathrm{R}$ an isotropic hardening variable, $p$ the accumulated plastic strain and $\mathrm{C}, \mathrm{D}, R_{0}, b$ and $Q$ are material coefficients. The simulated stress-strain loops, using the coefficients gathered in Table A1 are compared to measured stress-strain loops at cycle 1, and 299 on Figure A1. The material exhibits cyclic softening, and thus parameter $\mathrm{Q}$ is negative.

\begin{tabular}{|c|c|c|c|c|c|}
\hline $\mathrm{E}(\mathrm{GPa})$ & $\mathrm{R}(\mathrm{MPa})$ & $\mathrm{b}$ & $\mathrm{Q}(\mathrm{MPa})$ & $\mathrm{C}(\mathrm{MPa})$ & $\mathrm{D}$ \\
\hline 182 & 387 & 0,478 & $-83,4$ & 67212 & 387 \\
\hline
\end{tabular}

Table A1. Identified coefficients for the constitutive equations
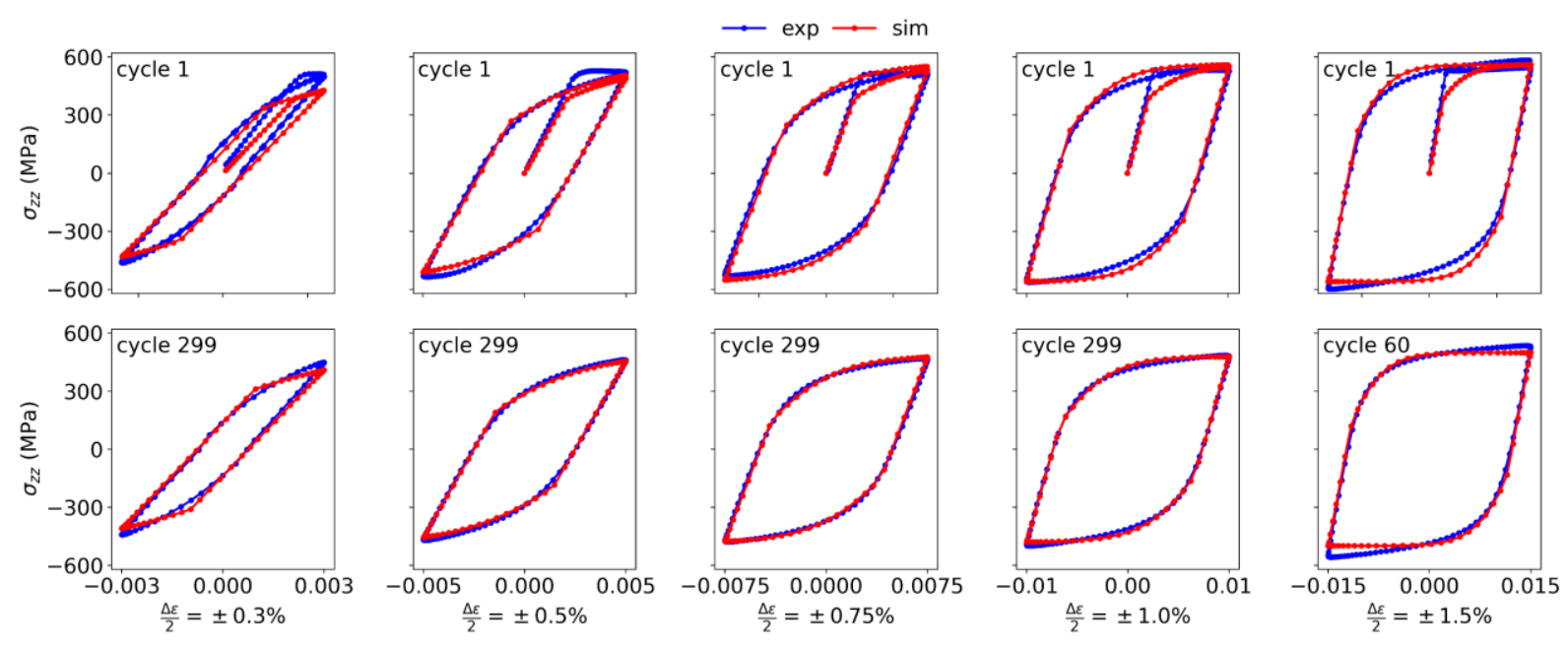

Figure A1 : Comparison of simulated and measured stress-strain loops at selected cycles, for strain ranges of $\pm 0.3 \%, \pm 0.5 \%, \pm 0.75 \%, \pm 1.0 \%$ and $\pm 1.5 \%$

\section{REFERENCES}

[1] M. Fonte, M. de Freitas - Marine main engine crankshaft failure analysis: a case study $\begin{array}{llllll}\text { Engineering } & \text { Failure } & \text { Analysis } & 16 & \text { (2009) } & \text { 1940-1947. }\end{array}$ https://doi.org/10.1016/j.engfailanal.2008.10.013

[2] T. Lassen, A. Spagnoli - Fatigue crack paths in shafts subjected to bending and torsion Computer Science 2013

[3] G. Pantazopoulos , S. Papaefthymiou - Failure and fracture analysis of austenitic stainless steel marine propeller shaft - Journal of Failure, Analysis and Prevention 15 (2015) 762-767. https://doi.org/10.1007/s11668-015-0024-7

[4] M. Banuta, I. Tarquini - Fatigue failure of a drive shaft - Journal of Failure, Analysis and Prevention 12 (2012) 139-144. https://doi.org/10.1007/s11668-012-9551-7 
[5] P. Kettrakul, P. Promdirek - Failure analysis of propeller shaft used in the propulsion system of a fishing boat - Proc. 10 ${ }^{\text {th }}$ Thailand International Metallurgy Conference 5 (2018) 9624-9629. https://doi.org/10.1016/j.matpr.2017.10.149

[6] G. Vizentin, G. Vukelic, M. Srok - Common failures of ship propulsion shafts - Scientific Journal of Maritime Research 31 (2017) 85-90. http://dx.doi.org/10.31217/p.31.2.1

[7] J. Shi, N. Ding, N. Xu, W. Guo, L. Liu, L. Chen, X. Wu, Q. Zang, C-M L. Wu - Fretting fatigue fracture of the supporting shaft in a rotary kiln - Engineering Failure Analysis 82 (2017) 474-480. https://doi.org/10.1016/j.engfailanal.2017.02.023

[8] M.N. Tamin, M.A. Hamzah - Fatigue failure analysis of a centrifugal pump shaft IntechOpen (2017) Failure Analysis and Prevention. https://doi.org/10.5772/intechopen.70672

[9] Z. Zhang, A. Yin, T. Han , A.C.C. Tan - Fracture analysis of wind turbine main shaft $\begin{array}{lllll}\text { Engineering } & \text { Failure } & \text { Analysis } & 34 & \text { (2013) }\end{array}$ https://doi.org/10.1016/j.engfailanal.2013.07.014

[10] P. Bilmes, C. Llorente, J.M. Echarri, T. Echarri, A. Martinez, J. Zuzulich - Root cause analysis of cracking in shaft end and coupling of a high-power generator - Journal of Failure, Analysis and Prevention 18, (2018) 727-732. http://dx.doi.org/10.1007/s11668-018-0468-7

[11] M.Y. Nikravesh, M.M. Sharafi - Failure of a steam turbine rotor due to a circumferential crack growth influenced by temperature and steady torsion - Engineering Failure Analysis 66, (2016) 296-311. https://doi.org/10.1016/j.engfailanal.2016.03.020

[12] K.N. Akhurst, T.C. Lindley, K.J. Nix - The effect of mode III loading on fatigue crack growth in a rotating shaft, Fatigue \& Fracture Engineering Materials \& Structures 6 (1983) 345348. https://doi.org/10.1111/j.1460-2695.1983.tb00349.x

[13] F. Hourlier, D. McLean, A. Pineau - Fatigue crack growth behaviour of Ti-5Al-2.5Sn alloy under complex stress (mode I + steady mode III), Metals Technology (1978), 154-158. https://doi.org/10.1179/mt.1978.5.1.154

[14] F. Hourlier, A. Pineau - Propagation of fatigue cracks under polymodal loading, Fatigue \& Fracture Engineering Materials \& Structures 5 (4), (1982) 287-302. http://dx.doi.org/10.1111/j.1460-2695.1982.tb01237.x

[15] F. Hourlier, H. d'Hondt, M. Truchon, A. Pineau - Fatigue crack path behavior under polymodal fatigue, multiaxial fatigue, ASTM STP 853, K. Miller \& M.W. Brown eds, ASTM, Philadelphia (1985) 228-248. https://doi.org/10.1520/STP36226S

[16] E.K. Tschegg, H.R. Mayer, M. Czegley, S.E. Stanzl - Influence of a constant mode III load on mode I fatigue crack growth thresholds, Proc. $3^{\text {rd }}$ International Conference on Biaxial/Multiaxial fatigue, Stuttgart, 1989

[17] Y.C. Lu, T. Chen, F.P.Yang, T. Lan - The retardation effect of static torsion on fatigue crack growth in strip steel, Fatigue \& Fracture Engineering Materials \& Structures $43 \quad$ (8), (2020) 1800-1813. https://doi.org/10.1111/ffe.13233

[18] X. Yu, A. Abel, Crack surface interference under cyclic mode I and steady mode II loading, Engng Fracture Mechanics 66 (2000) 503-535 
[19] B. R. You, S. B. Lee, Fatigue crack growth behaviour of SM45C steel under cyclic mode I with superimposed static mode II loadings, Fatigue Fract. Engng Mater. Struct. 20 (1997) 10591074

[20] S. Stanzl, M. Czegley, H.R. Mayer, E. Tschegg - Fatigue crack growth under combined mode I and mode II loading, Fracture mechanics: perspectives and directions. ed. R. Wei, R. Gangloff, ASTM International, (1989) p.479-496. https://doi.org/10.1520/STP18839S

[21] V. Doquet, Q.H. Bui, A. Constantinescu - Plasticity and asperity-induced fatigue crack closure under mixed-mode loading, International Journal of Fatigue 32 (10), (2010) 1612-1619. https://dx.doi.org/10.1016/j.ijfatigue.2010.02.011

[22] M. da Fonte, M. de Freitas, D. François - Fatigue crack growth under rotating bending and steady torsion, Proc. 4th International Conference on Biaxial/Multiaxial Fatigue, May 1994, Saint-Germain-en-Laye,

[23] M. da Fonte, M. de Freitas - Semi-elliptical fatigue crack growth under rotating or reversed bending combined with steady torsion, Fatigue \& Fracture Engineering Materials \& Structures 20, (1997) 895-906. https://doi.org/10.1111/j.1460-2695.1997.tb01533.x

[24] M. da Fonte, E. Gomes, M. de Freitas - Stress intensity factors for semi-elliptical surface cracks in round bars subjected to mode I (bending) and mode III (torsion) loading. Proc. 5th International Conference on Biaxial/Multiaxial Fatigue 1997, Cracovie, https://doi.org/10.1016/S1566$\underline{1369(99) 80019-3}$

[25] M. Fonte, L. Reis, F. Romeiro, B. Li et M. Freitas - The effect of steady torsion on fatigue crack growth in shafts - International Journal of Fatigue 28, (2006) 609-617. https://doi.org/10.1016/j.ijfatigue.2005.06.051

[26] F. Yang, Z. Kuang, V.N. Shlyannikov - Fatigue crack growth for straight-fronted edge crack in a round bar, Int. J. Fatigue 28, (2006) 431-437. https://doi.org/10.1016/j.ijfatigue.2005.07.036

[27] S. Suresh - Crack initiation in cyclic compression and its applications, Engineering Fracture Mechanics 21 (3), (1985) 453-463. https://doi.org/10.1016/S0013-7944(85)80038-2

[28] V.A. Popovich, T. Opraus, M. Janssen, B. Hu, A.C. Riemslag - The Use of Circumferentially Notched Tension (CNT) Specimen for Fracture Toughness Assessment of High Strength Steels, The Minerals, Metals \& Materials Society, TMS 2018 147th Annual Meeting \& Exhibition Supplemental Proceedings. http://dx.doi.org/10.1007/978-3-319-72526$\underline{0 \_47}$

[29] M.A. Ritter, M.O. Ritchie - On the calibration, optimization and use of d.c. electrical potential methods for monitoring mode III crack growth in torsionally loaded samples, Fatigue \& Fracture Engineering Materials \& Structures 5, (1982) 91-99. https://doi.org/10.1111/j.14602695.1982.tb01227.x

[30] H. Tada, P.C. Paris, G. Irwin - Stress Analysis of Cracks Handbook. ASME Press, 2000. https://doi.org/10.1115/1.801535

[31] ASTM E 647-08 Standard test method for measurement of fatigue crack growth rates, American Society for Testing and Materials, West Conshohocken, ASTM Int. 2009 N.D.

[32] M. Akama, A. Kiuchi - Long co-planar mode III fatigue crack growth under nonproportional mixed-mode loading in rail-steel, Proc. of the Institution of Mechanical Engineers, Part F: Journal of Rail and Rapid Transit 226 (5), (2012). https://doi.org/10.1177\%2F0954409712440397 
[33] I. Kim, Y Zhao, B Choi, J Mi Lee, K Lee, J.M. Lee - Numerical analysis of asymmetric fatigue crack growth behaviors of circular notched bar specimen resulting from various geometric misalignments, Engineering Fracture Mechanics 108, (2013) 50-64. https://doi.org/10.1016/j.engfracmech.2013.04.015

[34] J. Toribio, B. González, J.C. Matos - Crack tip field in eccentric circumferentially cracked round bar under tensile loading, Fatigue \& Fracture Engineering Materials \& Structures 41, (2018) 2153-2161. https://doi.org/10.1111/ffe.12817

[35] T. Bonniot, V. Doquet, S. H. Mai, Mixed mode II and III fatigue crack growth in a rail steel, Int. J. Fatigue 115 (2018) 42-52

[36] G. Xu, A.F. Bower, M. Ortiz - An analysis of non-planar crack growth under mixed mode loading, International Journal of Solids and Structures 31 (16), (1994) 2167-2193. https://doi.org/10.1016/0020-7683(94)90205-4

[37] J.B. Leblond, A. Karma, V. Lazarus - Theoretical analysis of crack front instability in mode I + III, Journal of the Mechanics and Physics of Solids 59 (9), (2011) 1872-1887. https://doi.org/10.1016/j.jmps.2011.05.011

[38] A. M. Al-Ani - A Two Parameter Characterisation of Defects (With Reference to Pipe Work), Ph.D.thesis, University of Glasgow, March 1991. http://theses.gla.ac.uk/id/eprint/72612

[39] B. Cotterel, J.R. Rice - Slightly curved or kinked cracks, International Journal of Fracture 16, (1980) 155-169. https://doi.org/10.1007/BF00012619

[40] J. Lemaitre, J.-L. Chaboche, Mechanics of solid materials, Cambridge University Press, 1900. https://doi.org/10.1017/CBO9781139167970 